Article

\title{
Differential Effects of Linkers on the Activity of Amphiphilic Tobramycin Antifungals
}

\author{
Marina Y. Fosso, Sanjib K. Shrestha, Nishad Thamban Chandrika, Emily K. Dennis, \\ Keith D. Green and Sylvie Garneau-Tsodikova * (iD) \\ Department of Pharmaceutical Sciences, College of Pharmacy, University of Kentucky, \\ Lexington, KY 40536-0596, USA; marina.fosso@uky.edu (M.Y.F.); sanjib.shrestha@uky.edu (S.K.S.); \\ nishad.tc@uky.edu (N.T.C.); emily.dennis@uky.edu (E.K.D.); keith.green@uky.edu (K.D.G.) \\ * Correspondence: sylviegtsodikova@uky.edu
}

Received: 2 April 2018; Accepted: 9 April 2018; Published: 13 April 2018

\begin{abstract}
As the threat associated with fungal infections continues to rise and the availability of antifungal drugs remains a concern, it becomes obvious that the need to bolster the antifungal armamentarium is urgent. Building from our previous findings of tobramycin (TOB) derivatives with antifungal activity, we further investigate the effects of various linkers on the biological activity of these aminoglycosides. Herein, we analyze how thioether, sulfone, triazole, amide, and ether functionalities affect the antifungal activity of alkylated TOB derivatives against 22 Candida, Cryptococcus, and Aspergillus species. We also evaluate their impact on the hemolysis of murine erythrocytes and the cytotoxicity against mammalian cell lines. While the triazole linker appears to confer optimal activity overall, all of the linkers incorporated into the TOB derivatives resulted in compounds that are very effective against the Cryptococcus neoformans species, with MIC values ranging from 0.48 to $3.9 \mu \mathrm{g} / \mathrm{mL}$.
\end{abstract}

Keywords: aminoglycosides; Aspergillus; Candida; Cryptococcus; cytotoxicity; hemolysis

\section{Introduction}

Aminoglycosides (AGs) represent a group of structurally diverse amino-modified sugars that have long been used for their antibacterial efficacy. Their broad-spectrum of activity against a plethora of pathogenic bacteria has, indeed, made them a valuable class of antibiotics [1]. However, as is the case with most antibiotics nowadays, AGs are suffering from the resurgence of bacterial resistance [2]. To circumvent this problem, several research groups have devoted efforts to the development of novel AGs with improved antibacterial activity [3]. Amphiphilic AGs in particular, which are AG-derived cationic amphiphiles, emerged as potent antimicrobial agents with a new mechanism of action [4]. They resulted from the incorporation of various hydrophobic groups to the polycationic and hydrophilic amikacin [5], tobramycin (TOB) [6-11], neamine [12-14], neomycin B [15-19], paromomycin $[20,21]$, and kanamycins A (KANA) and B (KANB) [22,23].

A growing interest in the identification of new targets of AGs [24] has recently led researchers to the investigation of AGs' action against fungi [23,25-30]. It is worth mentioning that the social and economic burden associated with fungal infections is considerable, both in medicine and agriculture. While the frequency of invasive fungal infections continues to rise, the number of antifungal agents available remains limited, calling for the development of additional effective antifungal drugs. Indeed, only three classes of antifungals are currently in clinical use [31]. These include the polyenes (for example, amphotericin B (AmB)), the azoles (for example, fluconazole, voriconazole (VOR), itraconazole, posaconazole), and the echinocandins (for example, caspofungin (CAS), micafungin, anidulafungin). These drugs exert their antifungal activity by either extracting ergosterol from 
the fungal plasma membrane [32], blocking the production of ergosterol through the inhibition of lanosterol 14 $\alpha$-demethylase [33], or inhibiting the biosynthesis of the fungal cell membrane component $(1,3)-\beta$-D-glucan [34], respectively. Unfortunately, resistance to these antifungal drugs has already been observed [35]. However, new strategies to combat fungal infections are being investigated, notably the development of derivatives of currently approved antifungals with improved activity and biological safety profiles [36-40], the combination therapy of current antifungal drugs working synergistically with other drugs [41], and the development of new classes of antifungal agents [42].

We have recently demonstrated that incorporating a linear alkyl chain (for example, the dodecyl group $\left(C_{12}\right)$ or tetradecyl group $\left.\left(C_{14}\right)\right)$ at the $6^{\prime \prime}$-position of TOB or KANB through a thioether linkage results in AGs with antifungal activity against $C$. albicans $[23,43]$. Although we found the TOB $\left(C_{14}\right)$ derivative to display stronger antifungal activity than TOB $\left(C_{12}\right)$, we elected to generate TOB $\left(C_{12}\right)$ analogues in this study because, as we previously demonstrated by investigating the hemolytic activity of $\mathrm{KANB}\left(\mathrm{C}_{12}\right)$ and $\left(\mathrm{C}_{14}\right)$, KANB $\left(\mathrm{C}_{12}\right)$ displayed lower hemolytic activity than $\mathrm{KANB}\left(\mathrm{C}_{14}\right)$. Herein, with the goal of improving on the activity of TOB $\left(C_{12}\right)$, we investigated the effects of different groups (for example, thioether, sulfone, triazole, amide, and ether) as linkers for the alkyl chain to the AG scaffold on the efficacy of TOB $\left(C_{12}\right)$ derivatives against 22 fungal strains. We investigated the hemolytic activity and cytotoxicity of the five most promising antifungals. We also performed time-kill studies and membrane permeabilization assays for the most active compound generated.

\section{Results and Discussion}

\subsection{Chemistry}

The synthesis started from the commercially available AG TOB. Modification at the $6^{\prime \prime}$-position of TOB requires the selective conversion of the $6^{\prime \prime}$-hydroxyl group into a good leaving group, which could be accomplished by Boc protection of the amino groups of TOB, followed by a reaction with 2,4,6-triisopropylbenzenesulfonyl chloride (TIPBSCl) in pyridine (Scheme 1). This gave the central intermediate 1 [44], which upon treatment with 1-dodecanethiol and $\mathrm{Cs}_{2} \mathrm{CO}_{3}$, afforded another intermediate compound $2[8,10]$. Treatment of compound $\mathbf{2}$ with trifluoroacetic acid (TFA) efficiently removed all the Boc protecting groups to give the target compound 3 [10], representing the TOB derivative with the thioether linkage. Furthermore, $S$-oxidation of compound 2 with $m$-CPBA followed by TFA treatment yielded the target sulfone derivative 4 [8].

Compound 1 was also subjected to a $\mathrm{S}_{\mathrm{N}} 2$ nucleophilic displacement reaction in the presence of tetrabutylammonium azide (TBAA) to give the azido intermediate 5 [11]. Using copper sulfate and sodium L-ascorbate in DMF under microwave conditions, a click reaction between compound 5 and commercially available alkynes (1-dodecyne and 1-tetradecyne) afforded the intermediates $\mathbf{6} \mathbf{a}$ and $\mathbf{6 b}$ [11], respectively, whose TFA treatment gave the target triazole derivatives $\mathbf{7 a}$ and $\mathbf{7 b}$ [11], respectively. The design for compound $\mathbf{7 a}\left(\mathrm{C}_{10}\right.$-triazole), which is two-carbon shorter than compound $\mathbf{7 b}$, stems from the need to investigate whether or not the nitrogen atoms N2 and N3 of the triazole ring contribute to the overall length of the alkyl side chain. Compound $\mathbf{5}$ was also subjected to Staudinger reduction that converted the $6^{\prime \prime}$-azido group into an amine, followed by amide coupling with lauric acid to yield compound 8 , which was then converted to the target amide derivative 9 .

The synthesis of the TOB derivative with the ether linkage started with the conversion of TOB into the known perazide $\mathbf{1 0}$ [45] with triflyl azide, which was then reacted with pivaloyl chloride to afford the 6"-O-pivalate $\mathbf{1 1}$ (Scheme 2). Benzyl protection of the remaining hydroxyl groups afforded compound 12, which was then subjected to base hydrolysis of the pivaloyl group to give compound 13, with a free $6^{\prime \prime}$-hydroxyl group. Alkylation of compound 13 in the presence of sodium hydride and 1-bromododecane then afforded compound 14. Staudinger reduction of azide to amine, hydrogenolysis, and Boc protection of the free amino groups gave compound 15, which was converted to the target $6^{\prime \prime}$-O-dodecyl-TOB derivative 16 through TFA deprotection. 

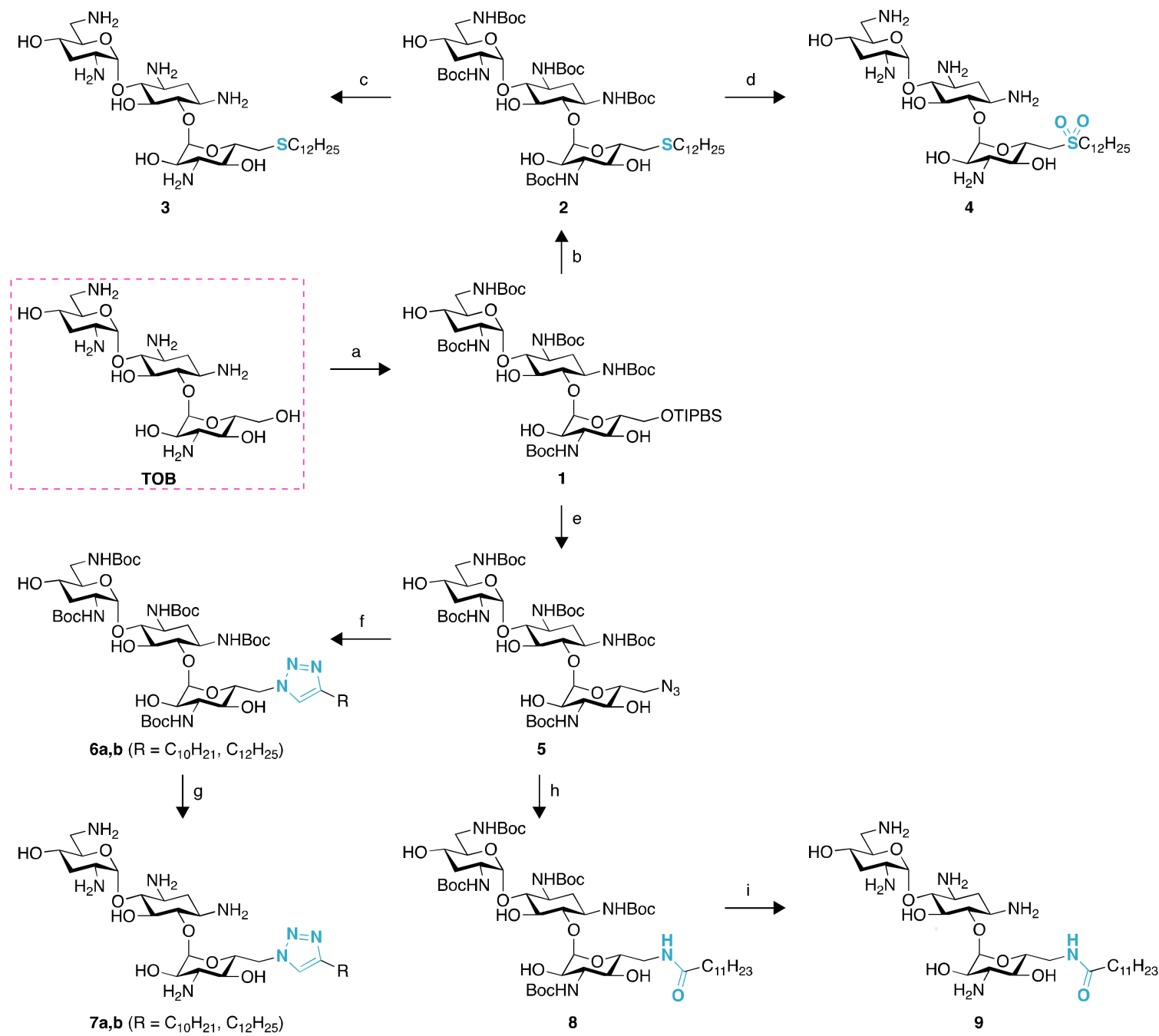

Scheme 1. The synthesis of tobramycin (TOB) derivatives 3, 4, 7a, 7b, and 9. Reagents: (a) TIPBSCl, pyridine, 59\%; (b) $\mathrm{C}_{12} \mathrm{H}_{25} \mathrm{SH}, \mathrm{Cs}_{2} \mathrm{CO}_{3}, \mathrm{~N}, \mathrm{~N}$-dimethylformamide (DMF), 79\%; (c) Trifluoroacetic acid (TFA), 61\%; (d) $m$-CPBA/ $\mathrm{CHCl}_{3}$ then TFA, 66\%; (e) Tetrabutylammonium azide (TBAA), DMF, $75{ }^{\circ} \mathrm{C}, 65 \%$; (f) $\mathrm{R}-\mathrm{CCH}, \mathrm{CuSO}_{4} \cdot 5 \mathrm{H}_{2} \mathrm{O}$, sodium L-ascorbate, DMF, microwave, 57-63\%; (g) TFA, 94\%-quantitative; (h) $\mathrm{PMe}_{3}, \mathrm{THF} / \mathrm{H}_{2} \mathrm{O}, 50{ }^{\circ} \mathrm{C}$ then $\mathrm{C}_{11} \mathrm{H}_{23} \mathrm{CO}_{2} \mathrm{H}, \mathrm{EDC} \cdot \mathrm{HCl}, \mathrm{HOBt}, \mathrm{DIPEA}, \mathrm{DMF}, 55 \%$; (i) TFA, 93\%. 


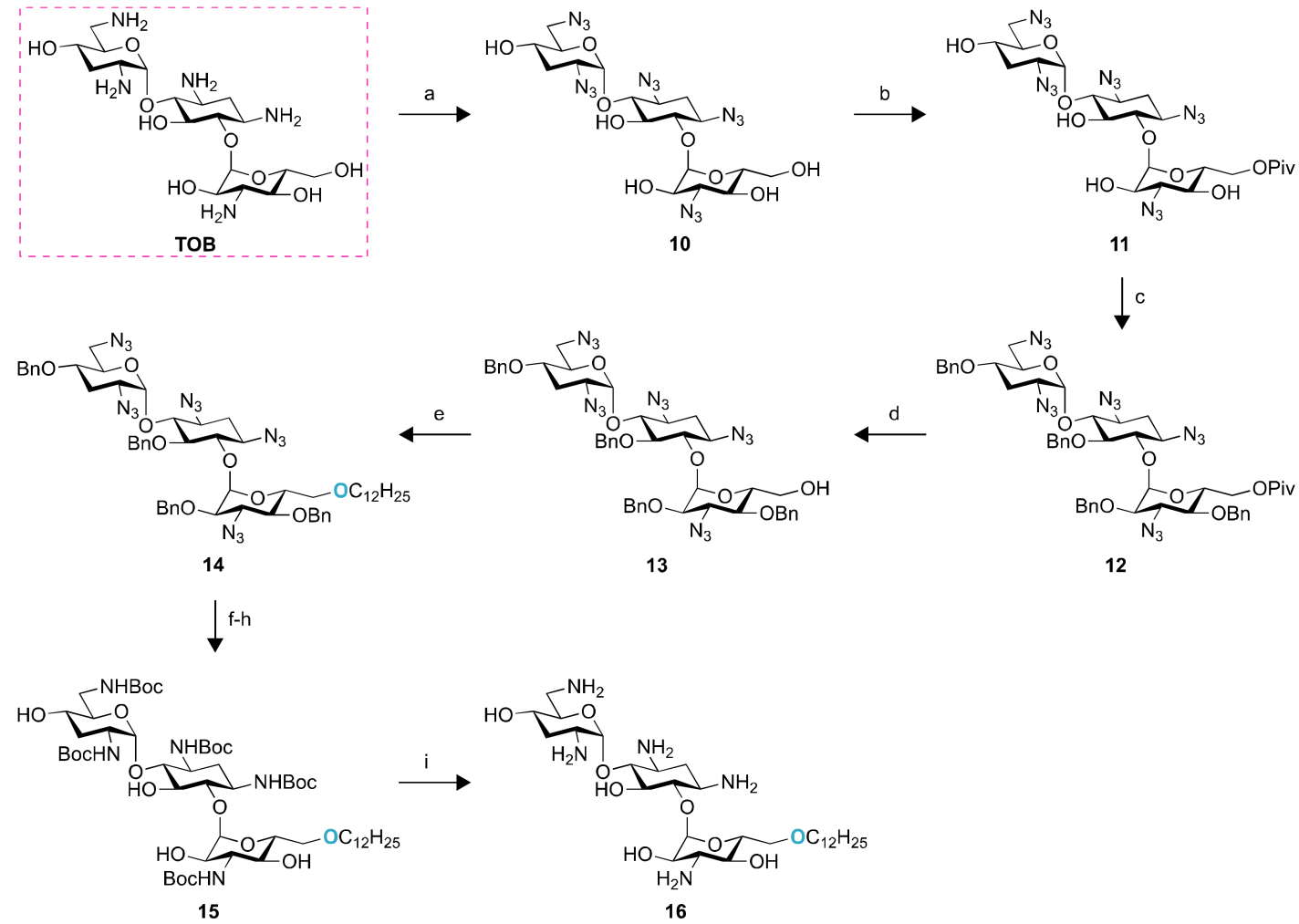

Scheme 2. The synthesis of TOB derivative 16. Reagents: (a) $\mathrm{NaN}_{3}, \mathrm{Tf}_{2} \mathrm{O}, \mathrm{H}_{2} \mathrm{O}, \mathrm{CH}_{2} \mathrm{Cl}_{2}$ then $\mathrm{ZnCl}_{2}$, $\mathrm{Et}_{3} \mathrm{~N}, \mathrm{H}_{2} \mathrm{O}, \mathrm{MeOH}, 92 \%$; (b) PivCl, pyridine, $0{ }^{\circ} \mathrm{C}, 63 \%$; (c) $\mathrm{NaH}, \mathrm{BnBr}, \mathrm{TBAI}, \mathrm{DMF}, 76 \%$; (d) $\mathrm{Na}, \mathrm{MeOH}$, $60{ }^{\circ} \mathrm{C}, 81 \%$; (e) $\mathrm{NaH}, \mathrm{C}_{12} \mathrm{H}_{25} \mathrm{Br}$, TBAI, DMF, 82\%; (f) $\mathrm{PMe}_{3}, \mathrm{NaOH}, \mathrm{THF}$; (g) $\mathrm{Pd}(\mathrm{OH})_{2} / \mathrm{C}, \mathrm{H}_{2}, \mathrm{AcOH}$, $\mathrm{H}_{2} \mathrm{O}$; (h) $\mathrm{Boc}_{2} \mathrm{O}, \mathrm{Et}_{3} \mathrm{~N}, \mathrm{THF}, 60{ }^{\circ} \mathrm{C}, 32 \%$ over 3 steps; (i) $\mathrm{TFA}, 96 \%$.

\subsection{In Vitro Antifungal Activity}

The minimum inhibitory concentration (MIC) values of TOB and its derivatives $3, \mathbf{4}, \mathbf{7 a}, \mathbf{7 b}, \mathbf{9}$, and 16 were determined (Tables 1-3). We focused our study on the Candida (albicans and non-albicans), Cryptococcus, and Aspergillus species, which are medically significant fungal pathogens [46]. We also included the FDA-approved antifungal drug CAS as a control; it is used clinically in the treatment of fungal infections caused by Candida and Aspergillus species.

Our initial study targeted the $C$. albicans species since, in addition to offering a point of comparison with our previously published data on compound 3 [43], they are responsible for the largest number of Candida-related fungal infections in humans [47]. They account for many invasive fungal infections observed in intensive care units [48]. These included the following seven strains: C. albicans ATCC 10231 (strain A), C. albicans ATCC 64124 (strain B), C. albicans ATCC MYA-2876 (strain C), C. albicans ATCC 90819 (strain D), C. albicans ATCC MYA-2310 (strain E), C. albicans ATCC MYA-1237 (strain F), and C. albicans ATCC MYA-1003 (strain G). While the derivatives appeared to be less effective than CAS, all but compound $\mathbf{1 6}$ were better than the parent TOB against all C. albicans strains tested (Table 1). Indeed, TOB was inactive against all strains tested with MIC values $>62.5 \mu \mathrm{g} / \mathrm{mL}$. On the other hand, compound $\mathbf{7 b}$, with the triazole linkage, was the most active derivative with MIC values ranging from 3.9 to $15.6 \mu \mathrm{g} / \mathrm{mL}$, which corresponds to a 4 - to $>16$-fold improvement compared to TOB. The thioether derivative 3 and the sulfone 4 were the next most active derivatives. The MIC values for compound 3 corresponded within 2-fold to those previously published [43]. The MIC values of compounds 3 and $4(7.8-31.3 \mu \mathrm{g} / \mathrm{mL})$ were also not much different from each other, always within a 2 -fold dilution, indicating that metabolic $S$-oxidation might not have a noticeable effect on potency. This is in agreement with our previous observation of KANB with a $\mathrm{C}_{12}$ chain in a thioether linkage at 
the $6^{\prime \prime}$-position and its oxidized counterpart as antifungals [23]. Compound $16\left(\mathrm{C}_{12}\right.$-ether $)$ was the least effective (MIC values $\geq 62.5 \mu \mathrm{g} / \mathrm{mL}$ ) followed by the $\mathrm{C}_{10}$-triazole $7 \mathrm{a}$ (MIC values ranging from 31.3 to $62.5 \mu \mathrm{g} / \mathrm{mL}$ ) and the $\mathrm{C}_{11}$-amide 9 (MIC values ranging from 15.6 to $62.5 \mu \mathrm{g} / \mathrm{mL}$ ).

Table 1. The minimum inhibitory concentration (MIC) values a (in $\mu \mathrm{g} / \mathrm{mL}$ ) determined for tobramycin (TOB); its derivatives $3, \mathbf{4}, \mathbf{7 a}, \mathbf{7 b}, \mathbf{9}$, and $\mathbf{1 6}$; as well as CAS, against a panel of seven C. albicans strains.

\begin{tabular}{cccccccc}
\hline \multicolumn{7}{c}{ Yeast Strains } \\
\hline Cpd \# & A & B & C & D & E & F & G \\
\hline TOB & $>62.5$ & $>62.5$ & $>62.5$ & $>62.5$ & $>62.5$ & $>62.5$ & $>62.5$ \\
$\mathbf{3}$ & 15.6 & 15.6 & 15.6 & 15.6 & 15.6 & 7.8 & 15.6 \\
$\mathbf{4}$ & 15.6 & 31.3 & 15.6 & 15.6 & 15.6 & 15.6 & 15.6 \\
$\mathbf{7 a}$ & 31.3 & 31.3 & 62.5 & 62.6 & 31.3 & 62.5 & 62.5 \\
$\mathbf{7 b}$ & 3.9 & 3.9 & 15.6 & 15.6 & 7.8 & 7.8 & 7.8 \\
$\mathbf{9}$ & 31.3 & 15.6 & 31.3 & 62.5 & 31.3 & 31.3 & 31.3 \\
$\mathbf{1 6}$ & 62.5 & 62.5 & $>62.5$ & 62.5 & 62.5 & 62.5 & 62.5 \\
CAS & 0.975 & 0.24 & 0.06 & 0.12 & 0.12 & 0.24 & 0.48 \\
\hline
\end{tabular}

a MIC-0 values are reported for all compounds tested. Yeast strains: $\mathbf{A}=$ Candida albicans ATCC 10231, $\mathbf{B}=$ C. albicans ATCC 64124, C = C. albicans ATCC MYA-2876(S), $\mathbf{D}=$ C. albicans ATCC 90819(R), $\mathrm{E}=$ C. albicans ATCC MYA-2310(S), $\mathbf{F}=$ C. albicans ATCC MYA-1237(R), $\mathbf{G}=$ C. albicans ATCC MYA-1003(R). NOTE: Here, the (S) and (R) indicate that ATCC reports these strains to be susceptible (S) or resistant (R) to itraconazole and fluconazole.

These promising results encouraged us to expand our study to nine non-albicans Candida strains, including C. glabrata ATCC 2001 (strain H), C. krusei ATCC 6258 (strain I), C. parapsilosis ATCC 22019 (strain J), three C. glabrata clinical isolates (CG1-3), and three C. parapsilosis clinical isolates (CP1-3) (Table 2). As observed with the $C$. albicans yeast strains, the compounds $3, \mathbf{4}, \mathbf{7 a}, 7 \mathbf{b}, \mathbf{9}$, and 16 were more active than TOB, but less active than CAS. Once again, compound $\mathbf{7 b}$, with the triazole linkage, displayed the lowest MIC values overall (1.95-7.8 $\mu \mathrm{g} / \mathrm{mL})$, representing an 8- to $>32$-fold improvement compared to TOB (MIC values $>62.5 \mu \mathrm{g} / \mathrm{mL}$ ). The thioether 3 and the sulfone 4 also exhibited good activity (MIC values ranging from 3.9 to $15.6 \mu \mathrm{g} / \mathrm{mL}$ ), followed by the amide 9 (MIC values ranging from 7.8 to $31.3 \mu \mathrm{g} / \mathrm{mL}$ ), the $\mathrm{C}_{10}$-triazole $7 \mathrm{a}$ (MIC values ranging from 15.6 to $62.5 \mu \mathrm{g} / \mathrm{mL}$ ), and the $\mathrm{C}_{12}$-ether 16 (MIC values ranging from 31.3 to $62.5 \mu \mathrm{g} / \mathrm{mL}$ ).

Table 2. The MIC values a (in $\mu \mathrm{g} / \mathrm{mL}$ ) determined for TOB; its derivatives 3, 4, 7a, 7b, 9, and 16; as well as CAS, against a panel of nine non-albicans Candida and three strains of Cryptococcus neoformans.

\begin{tabular}{|c|c|c|c|c|c|c|c|c|c|c|c|c|}
\hline \multirow[b]{3}{*}{ Cpd \# } & \multicolumn{12}{|c|}{ Yeast Strains } \\
\hline & \multicolumn{9}{|c|}{ Non-albicans Candida } & \multicolumn{3}{|c|}{ Cryptococcus neoformans } \\
\hline & CG1 & CG2 & CG3 & $\mathbf{H}$ & I & $\mathbf{J}$ & CP1 & $\mathrm{CP} 2$ & CP3 & CN1 & $\mathrm{CN} 2$ & $\mathrm{CN} 3$ \\
\hline ТОВ & $>62.5$ & $>62.5$ & $>62.5$ & $>62.5$ & $>62.5$ & $>62.5$ & $>62.5$ & $>62.5$ & $>62.5$ & $>62.5$ & $>62.5$ & $>62.5$ \\
\hline 3 & 15.6 & 7.8 & 15.6 & 7.8 & 3.9 & 7.8 & 15.6 & 7.8 & 15.6 & 0.975 & 0.48 & 0.48 \\
\hline 4 & 7.8 & 3.9 & 3.9 & 15.6 & 7.8 & 7.8 & 3.9 & 3.9 & 7.8 & 1.95 & 0.48 & 0.975 \\
\hline $7 a$ & 31.3 & 15.6 & 15.6 & 62.5 & 15.6 & 15.6 & 15.6 & 15.6 & 31.3 & 0.975 & 0.975 & 0.48 \\
\hline $7 \mathbf{b}$ & 3.9 & 3.9 & 3.9 & 7.8 & 3.9 & 1.95 & 3.9 & 1.95 & 7.8 & 0.48 & 0.48 & 0.975 \\
\hline 9 & 15.6 & 15.6 & 15.6 & 31.3 & 15.6 & 7.8 & 31.3 & 15.6 & 31.3 & 0.975 & 0.975 & 0.975 \\
\hline 16 & $>62.5$ & 62.5 & 62.5 & 62.5 & 31.3 & 31.3 & 62.5 & 62.5 & 62.5 & 1.95 & 0.975 & 3.9 \\
\hline CAS & 1.95 & 0.24 & 0.975 & 0.06 & 0.48 & 1.95 & 0.48 & 0.48 & 0.48 & 15.6 & 31.3 & 15.6 \\
\hline
\end{tabular}

${ }^{\text {a }}$ MIC-0 values are reported for all compounds tested. Yeast strains: CG1-3 = Candida glabrata clinical isolates, CP1-3 = Candida parapsilosis clinical isolates, CN1-3 = Cryptococcus neoformans clinical isolates, $\mathbf{H}=$ Candida glabrata ATCC 2001, I = Candida krusei ATCC 6258, J = Candida parapsilosis ATCC 22019.

We had previously observed that Cryptococcus neoformans MYA-895 was exceptionally sensitive to compound 3, with a low MIC value of $1.95 \mu \mathrm{g} / \mathrm{mL}$ [43]. We thus decided to assess the potency of compounds 3, 4, 7a, $\mathbf{7 b}, \mathbf{9}$, and $\mathbf{1 6}$ against $C$. neoformans clinical isolates CN1-3 (Table 2). Interestingly, all synthesized TOB derivatives displayed excellent activity, with MIC values ranging from 0.48 to $3.9 \mu \mathrm{g} / \mathrm{mL}$, while TOB and CAS showed low to no activity. This represents a 16- to $>128$-fold improvement compared 
to TOB (MIC values $>62.5 \mu \mathrm{g} / \mathrm{mL}$ ). C. neoformans is responsible for cryptococcosis, which remains a significant cause of mortality and morbidity in immunocompromised individuals [49].

Finally, based on the very promising and encouraging results obtained against the $C$. neoformans clinical isolates, we decided to assess the antifungal activity of the derivatives generated against other types of fungal strains. We opted for the filamentous fungi Aspergillus flavus ATCC MYA-3631 (strain K), Aspergillus nidulans ATCC 38163 (strain L), and Aspergillus terreus ATCC MYA-3633 (strain M) (Table 3). In these cases, all the TOB derivatives, with the exception of compound 16, were better than both TOB and CAS, with a trend similar to that observed with the C. albicans and non-albicans Candida strains. Furthermore, while A. terreus ATCC MYA-3633 (strain M) was not sensitive to the TOB derivatives, compounds $3, \mathbf{4}, \mathbf{7 a}, \mathbf{7 b}$, and $\mathbf{9}$ showed moderate activity against $A$. flavus ATCC MYA-3631 (strain K) (MIC values ranging from 7.8 to $31.3 \mu \mathrm{g} / \mathrm{mL}$ ) and good activity against $A$. nidulans ATCC 38163 (strain L) (MIC values ranging from 1.95 to $3.9 \mu \mathrm{g} / \mathrm{mL}$ ). Compound 16 only showed good activity against $A$. nidulans ATCC 38163 (strain L) with an MIC value of $3.9 \mu \mathrm{g} / \mathrm{mL}$.

Table 3. The MIC values a (in $\mu \mathrm{g} / \mathrm{mL}$ ) determined for TOB; its derivatives 3, 4, 7a, 7b, 9, and 16; as well as CAS, against a panel of three Aspergillus strains.

\begin{tabular}{cccc}
\hline & \multicolumn{3}{c}{ Filamentous Strains } \\
\hline Cpd \# & K & L & M \\
\hline TOB & $>62.5$ & $>62.5$ & $>62.5$ \\
$\mathbf{3}$ & 15.6 & 3.9 & $>62.5$ \\
$\mathbf{4}$ & 31.3 & 3.9 & 62.5 \\
$\mathbf{7 a}$ & 31.3 & 3.9 & $>62.5$ \\
$\mathbf{7 b}$ & 7.8 & 1.95 & 62.5 \\
$\mathbf{9}$ & 31.3 & 3.9 & $>62.5$ \\
$\mathbf{1 6}$ & $>62.5$ & 3.9 & $>62.5$ \\
CAS & $>31.3$ & $>31.3$ & $>31.3$ \\
\hline
\end{tabular}

a MIC-0 values are reported for all compounds tested. Filamentous strains: $\mathbf{K}=$ Aspergillus flavus ATCC MYA-3631, $\mathbf{L}=$ Aspergillus nidulans ATCC 38163, $\mathbf{M}=$ Aspergillus terreus ATCC MYA-3633.

In light of these results, it appears that the linkers play a major role in the activity of alkylated TOB derivatives, with triazole $>$ "better than" thioether/sulfone $>$ amide $>$ ether. This may stem from the distinct ability of these linkers to form interactions with the polar lipid head groups of fungi. Indeed, with its three nitrogen atoms, the triazole ring may form more hydrogen bonds than the sulfone which has two oxygens, the amide with a nitrogen and an oxygen, and the ether with only an oxygen atom. It is worth mentioning that, while compound $7 \mathrm{~b}\left(\mathrm{C}_{12}\right.$-triazole $)$ was the most effective at inhibiting the growth of yeasts and filamentous fungi, compound $7 \mathbf{a}\left(\mathrm{C}_{10}\right.$-triazole $)$ was the least effective of all six TOB derivatives synthesized (except compound 16). This is no surprise as it is in accordance with the chain length-dependent antifungal activity observed with other amphiphilic AGs [23,43]. Indeed, amphiphilic AGs bear a hydrophilic core structure, which is rich in polar hydroxyl and amino groups that are positively charged under physiological conditions, and a lipophilic alkyl chain capable of interacting with the lipid-rich fungal cell membrane. As the length of the alkyl chain increases, the ability of amphiphilic AGs to puncture the lipid bilayers also increases, which may result in an enhanced cell membrane perturbation, a mechanism well-known for this type of molecules [8,27]. This also shows that the additional atoms N2 and N3 of the triazole ring do not contribute to the overall length of the alkyl chain.

\subsection{Hemolysis}

As potential antifungal agents, it is necessary to assess the ability of the synthesized compounds to selectively target fungal membranes. Since compound $\mathbf{1 6}$ was in general as inactive as the parent AG TOB, we decided to focus our efforts on the remaining TOB derivatives. We performed a hemolytic assay of the active TOB derivatives $\mathbf{3}, \mathbf{4}, \mathbf{7 a}, \mathbf{7 b}$, and $\mathbf{9}$ using murine red blood cells (mRBCs) (Figure 1 
and Table S1). Although these amphiphilic TOB derivatives appear to affect mRBCs more than the parent TOB, they all displayed relatively lower hemolytic activity compared to AmB, which is an FDA-approved antifungal prescription medicine. Overall, the following trend was observed: $7 \mathrm{a}\left(\mathrm{C}_{10}\right.$-triazole $)<$ "less hemolytic than" 9 ( $\mathrm{C}_{11}$-amide $)<4\left(\mathrm{C}_{12}\right.$-sulfone $)<3$ ( $\mathrm{C}_{12}$-thioether $)<\mathbf{7 b}$ $\left(\mathrm{C}_{12}\right.$-triazole). Once again, we noticed a chain length-dependent effect on hemolysis, as previously observed with KANB-derived cationic amphiphiles [23]. It also appeared that the sulfone and amide linkers may impart less hemolysis than the thioether and triazole ones. Oxidation of the thioether derivative 3 to its corresponding sulfone 4 also seemed to lessen the hemolytic activity, suggesting that metabolic $S$-oxidation may not be detrimental in this case. While the sulfone derivative 4 and the amide 9 lysed $\sim 15-25 \%$ and $\sim 18-32 \%$ of mRBCs, respectively, at their MIC values against all seven C. albicans strains, the thioether derivative 3 and the triazole $7 \mathrm{~b}$ lysed $\sim 19-46 \%$ and $\sim 13-41 \%$ of mRBCs, respectively. At their MIC values against non-albicans Candida strains, the sulfone derivative 4 and the amide 9 lysed $\sim 6-11 \%$ and $\sim 18-26 \%$ of mRBCs, respectively, while the thioether derivative 3 and the triazole $7 \mathbf{b}$ lysed $\sim 19-46 \%$ and $\sim 14-25 \%$ of mRBCs, respectively. While more hemolysis was observed at their MIC values against the Aspergillus strains ( $4-32 \%$ for compounds 4 and 9 , and $\sim 12-74 \%$ for compounds 3 and $7 \mathbf{b}$ ), the TOB derivatives $3,4,7 a, 7 b$, and 9 caused little to no hemolysis when tested at their MIC values against C. neoformans, only lysing up to $13 \%$ of $\mathrm{mRBCs}$ at $3.9 \mu \mathrm{g} / \mathrm{mL}$, which represents 2- to 8-fold their MIC values against the three clinical isolates tested. The generally low hemolytic activity observed strengthens the potential application of the newly synthesized TOB derivatives as antifungal agents against the $C$. neoformans species.

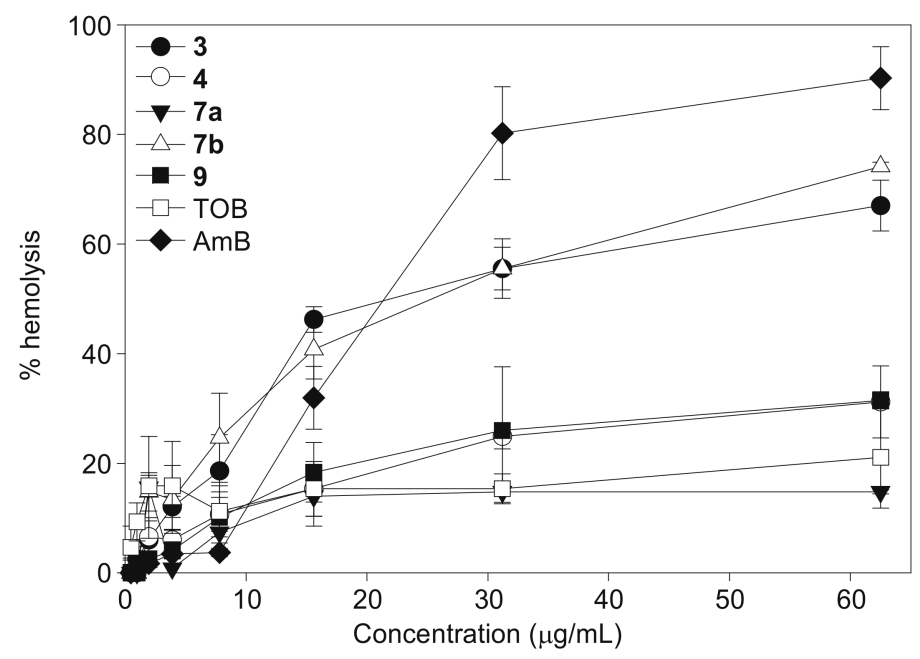

Figure 1. The hemolytic activity of tobramycin (TOB); its derivatives $3, \mathbf{4}, \mathbf{7 a}, \mathbf{7 b}$, and $\mathbf{9}$; as well as AmB on mRBCs. Note: the exact values used to generate this graph are presented in Table S1.

\subsection{Cytotoxicity}

To further evaluate the potential safety of the TOB derivatives $3,4,7 \mathbf{a}, 7 \mathbf{b}$, and $\mathbf{9}$, we assessed the cytotoxicity of these compounds against two mammalian cell lines, BEAS-2B and A549 (Figure 2). Like the parent AG TOB, these derivatives displayed little to no toxicity against both cell lines. Indeed, compounds 4 (sulfone), $7 \mathbf{a}\left(\mathrm{C}_{10}\right.$-triazole), $7 \mathbf{b}\left(\mathrm{C}_{12}\right.$-triazole), and 9 (amide) all had $\mathrm{IC}_{50}$ values $>62.5 \mu \mathrm{g} / \mathrm{mL}$, which were 1- to 16 -fold higher than their antifungal MIC values against the C. albicans species. Only compound 3 (thioether) had an $\mathrm{IC}_{50}$ value in the range of $31.3-62.5 \mu \mathrm{g} / \mathrm{mL}$ in BEAS-2B cells. This observed selectivity of the TOB derivatives in targeting fungal cells in the presence of mammalian cells may stem from the difference in lipid composition of the cell membranes in fungi and humans [50]. 

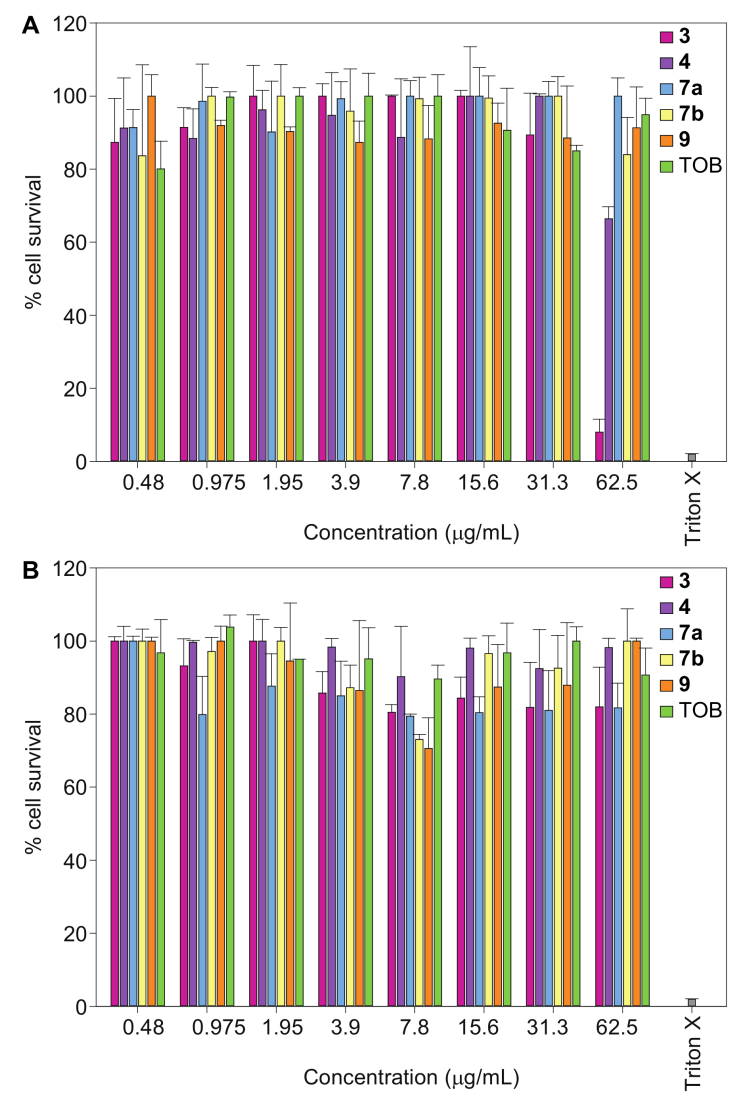

Figure 2. The mammalian cell cytotoxicity of $\mathrm{TOB}$ and its derivatives $\mathbf{3}, \mathbf{4}, \mathbf{7 a}, \mathbf{7 b}$, and $\mathbf{9}$ against (A) the BEAS-2B cell line and (B) the A549 cell line.

\subsection{Time-Kill Studies}

In light of the results presented so far, we selected the most promising compound $7 \mathbf{b}$ for further investigations. We evaluated the antifungal potency of $7 \mathbf{b}\left(\mathrm{C}_{12}\right.$-triazole $)$ by determining its time-kill course against a representative C. albicans strain, ATCC 10231 (strain A); a representative non-albicans Candida strain, C. parapsilosis ATCC 22019 (strain J); and a representative non-Candida yeast, $C$. neoformans (strain CN1) over a 24-h period. We also included the parent AG TOB and the triazole antifungal agent VOR as controls in our study (Figure 3). While TOB did not affect the growth of any of the tested fungal strains, its triazole derivative $7 \mathrm{~b}$ was able to reduce the $C$. albicans ATCC 10231 (strain A) CFU by $\geq 2 \log _{10}$ after $9 \mathrm{~h}$ of treatment at $3.9 \mu \mathrm{g} / \mathrm{mL}(1 \times \mathrm{MIC})$ and after $6 \mathrm{~h}$ of treatment at $15.6 \mu \mathrm{g} / \mathrm{mL}(4 \times$ MIC) (Figure 3a). This suggests a dose-dependent effect as previously observed with other antifungal amphiphilic AGs $[23,43]$. Furthermore, compound $\mathbf{7 b}$ showed a similar growth inhibitory effect to that of VOR, since the latter also reduced the CFU of $C$. albicans ATCC 10231 (strain A) by $\geq 2 \log _{10}$ after $9 \mathrm{~h}$ of treatment at its $1 \times$ MIC value of $1.0 \mu \mathrm{g} / \mathrm{mL}$ and maintained a fungistatic activity up to the 24-h period. Against C. parapsilosis ATCC 22019 (strain J), compound 7b displayed a fungistatic effect at $1.95 \mu \mathrm{g} / \mathrm{mL}(1 \times$ MIC) only for the first $3 \mathrm{~h}$ before the fungal cells followed a trend similar to the growth control (Figure $3 b$ ). A decrease in CFU by $\geq 2 \log _{10}$ was only observed after $24 \mathrm{~h}$ of treatment. Meanwhile, at $7.8 \mu \mathrm{g} / \mathrm{mL}(4 \times \mathrm{MIC})$, compound $7 \mathrm{~b}$ completely killed C. parapsilosis ATCC 22019 (strain J) after $24 \mathrm{~h}$. At $0.49 \mu \mathrm{g} / \mathrm{mL}(1 \times \mathrm{MIC})$, compound $7 \mathrm{~b}$ rapidly reduced the $\mathrm{CFU}$ of $\mathrm{C}$. neoformans (strain CN1) by $\geq 2 \log _{10}$ after $3 \mathrm{~h}$ of treatment (Figure $3 \mathrm{c}$ ). In addition, complete fungal cell death was observed as early as $6 \mathrm{~h}$ after the treatment at $0.49 \mu \mathrm{g} / \mathrm{mL}$ $(1 \times \mathrm{MIC})$ and $3 \mathrm{~h}$ after the treatment at $1.95 \mu \mathrm{g} / \mathrm{mL}(4 \times \mathrm{MIC})$, while TOB and VOR showed little to no growth inhibitory effect against $C$. neoformans (strain CN1). These results confirm that the TOB derivative $7 \mathbf{b}$ ( $\mathrm{C}_{12}$-triazole) exhibits better fungal growth inhibition than the parent AG TOB. 
Furthermore, compound $\mathbf{7 b}$ displayed a similar fungistatic effect to that of the FDA-approved triazole antifungal agent VOR against C. albicans ATCC 10231 (strain A) and C. parapsilosis ATCC 22019 (strain J), and an enhanced fungicidal effect against $C$. neoformans (strain CN1). The promise of $7 \mathbf{b}$ as a fungicidal agent against Cryptococcus sp. is highly encouraging.
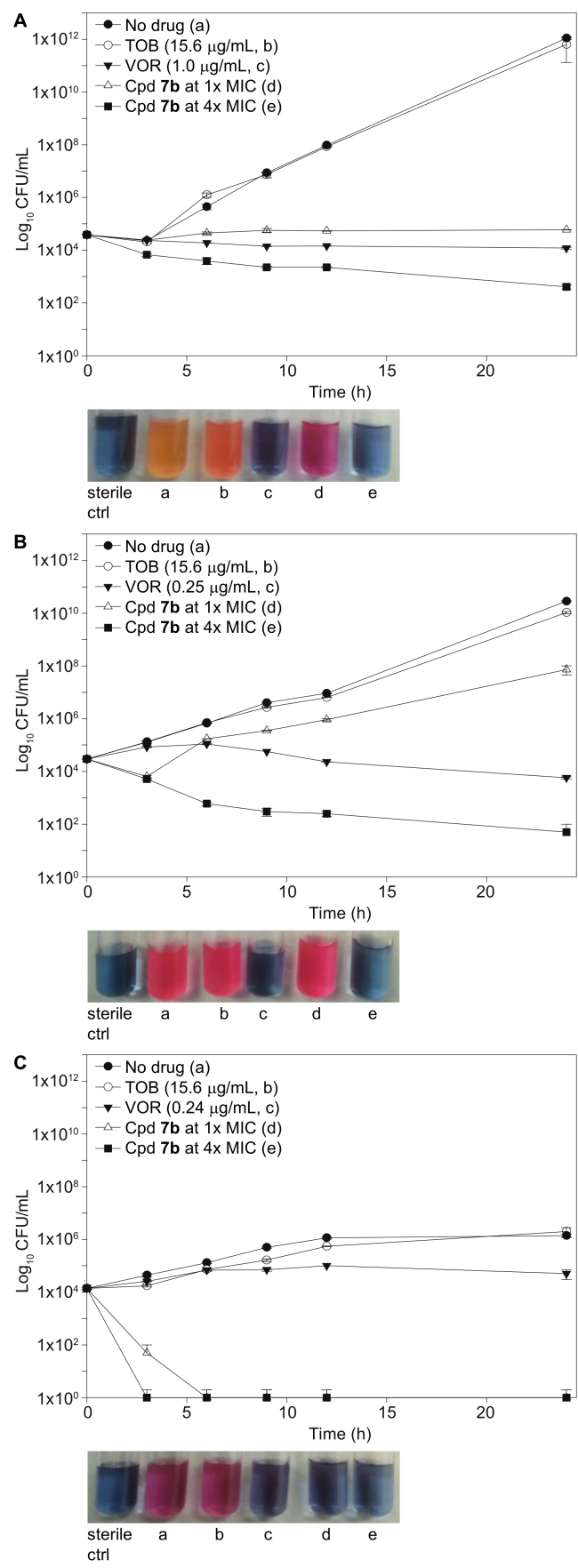

Figure 3. The representative time-kill studies of TOB derivative $7 \mathbf{b}$ against (A) C. albicans ATCC 10231 (strain A), (B) C. parapsilosis ATCC 22019 (strain J), and (C) Cryptococcus neoformans clinical isolate CN1. In all panels, the cultures were exposed to a no drug control (black circle), TOB at $15.6 \mu \mathrm{g} / \mathrm{mL}$ (white circle), VOR at 1.0 or $0.25 \mu \mathrm{g} / \mathrm{mL}$ (black inverted triangle), and $7 \mathbf{b}$ at $1 \times$ MIC (white triangle) and $4 \times$ MIC (black square). Each test tube represents the corresponding sample treated with resazurin, which was added for the visualization of fungal growth. Note: Blue = no fungal growth; orange-pink = fungal growth. 


\subsection{Antifungal Mechanism of Action}

We have previously shown that amphiphilic TOB derivatives, notably compound 3, exert their antifungal activity by perturbing the fungal cell membrane [43]. We then decided to evaluate the ability of the most potent compound $\mathbf{7 b}$ to affect the fungal membrane integrity. Using propidium iodide (PI), a dye that fluoresces upon binding nucleic acids in membrane-compromised cells [51], we observed that C. albicans ATCC 10231 (strain A) cells that were treated with compound 7b at concentrations equivalent to $2 \times \mathrm{MIC}$ or $4 \times \mathrm{MIC}$ allowed a larger influx of PI dye compared to the untreated cells or those treated with the parent TOB, which only showed negligible staining (Figure 4). Yeast killed by heat were used as the positive control. These results show that compound $7 \mathbf{b}$ also affects the fungal membrane permeability and is more effective than TOB in causing PI permeation into the azole-resistant C. albicans ATCC 10231 (strain A) cells.

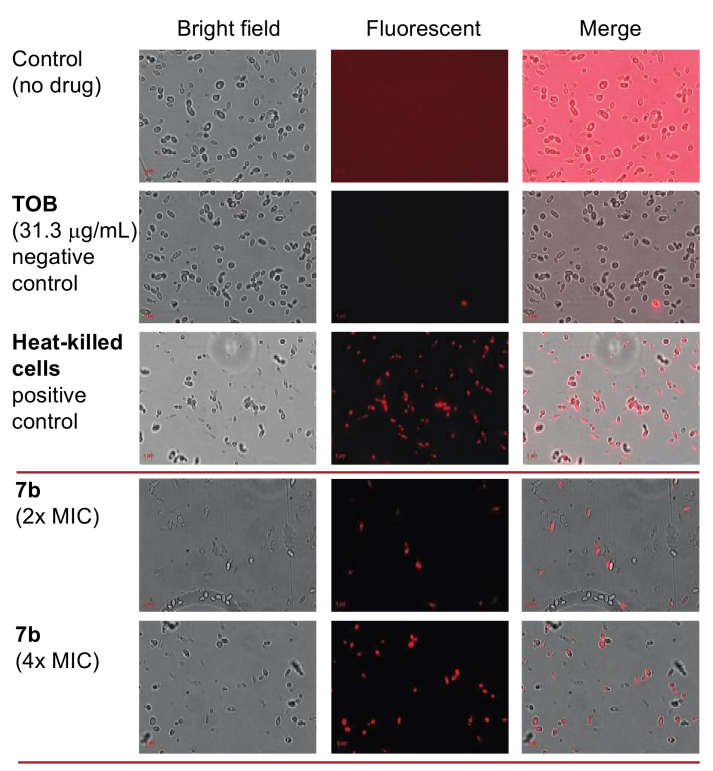

Figure 4. The representative dose-dependent membrane permeabilization effects of TOB and its derivative $7 \mathbf{b}$ on C. albicans ATCC 10231 (strain A). From top to bottom: propidium iodine (PI) dye uptake by yeast cells without drug, with TOB $(31.3 \mu \mathrm{g} / \mathrm{mL})$, killed by heat, with $7 \mathbf{b}(2 \times \mathrm{MIC})$, and with $7 \mathbf{b}(4 \times \mathrm{MIC})$.

\section{Conclusions}

In summary, we have synthesized six TOB derivatives with various linkers, including thioether, sulfone, triazole, amide, and ether. While the $\mathrm{C}_{12}$-triazole derivative $7 \mathbf{b}$ was the most potent, the $\mathrm{C}_{12}$-ether derivative $\mathbf{1 6}$ was the least effective at inhibiting the growth of several fungal strains. We also noticed a chain length-dependent effect on the antifungal activity. Furthermore, the active TOB derivatives displayed low hemolytic activity and low mammalian cell toxicity. Finally, the compounds generated were very active against $C$. neoformans clinical isolates, leaving the door open for a future (outside of the scope of this study) investigative avenue for the development of novel therapies for cryptococcosis.

\section{Materials and Methods}

\subsection{General Information}

Tobramycin (TOB) was purchased from AK Scientific (Union City, CA, USA). All other chemicals were purchased from Sigma-Aldrich (St. Louis, MO, USA) and used without further purification. Compounds 1 [44], 5 [11], and 10 [45] were prepared as previously described. All microwave 
irradiation experiments were performed in a sealed glass microwave reaction vial using a Biotage ${ }^{\circledR}$ Initiator $^{\mathrm{TM}}$ microwave synthesizer. Experiments were performed in temperature-control mode where the temperature was controlled using the built-in calibrated IR sensor. Chemical reactions were monitored by TLC (Merck, Kenilworth, NJ, USA, Silica gel $60 \mathrm{~F}_{254}$ ). Visualization was achieved using one of the following methods: $\mathrm{H}_{2} \mathrm{SO}_{4}$ stain $(5 \%$ in $\mathrm{MeOH})$, ceric molybdate stain $\left(5 \mathrm{~g}\left(\mathrm{NH}_{4}\right)_{2} \mathrm{Ce}\left(\mathrm{NO}_{3}\right)_{6}\right.$, $120 \mathrm{~g}\left(\mathrm{NH}_{4}\right)_{6} \mathrm{Mo}_{7} \mathrm{O}_{24} \cdot 4 \mathrm{H}_{2} \mathrm{O}, 80 \mathrm{~mL} \mathrm{H}_{2} \mathrm{SO}_{4}$, and $\left.720 \mathrm{~mL} \mathrm{H} \mathrm{H}_{2} \mathrm{O}\right)$, or $p$-anisaldehyde stain $(54 \mathrm{~mL} \mathrm{EtOH}$, $3 \mathrm{~mL} \mathrm{H}_{2} \mathrm{SO}_{4}$, and $3 \mathrm{~mL}$-anisaldehyde). Compounds were purified by $\mathrm{SiO}_{2}$ flash chromatography (Dynamic Adsorbents Inc., Norcross, GA, USA, Flash silica gel 32-62u). ${ }^{1} \mathrm{H}$ and ${ }^{13} \mathrm{C}-\mathrm{NMR}$ spectra were recorded on a Varian $400 \mathrm{MHz}$ spectrometer. High-resolution mass sprectra were recorded on an AB SCIEX Triple TOF 5600 System. All compounds tested for activity are $\geq 95 \%$ pure according to NMR spectra. TOB derivatives $3,4,7 \mathbf{a}, 7 \mathbf{b}, \mathbf{9}$, and 16 were dissolved in sterile $\mathrm{MQ}-\mathrm{H}_{2} \mathrm{O}$ at a final concentration of $10 \mathrm{mg} / \mathrm{mL}$ and stored at $-20^{\circ} \mathrm{C}$.

The antifungal agent caspofungin (CAS) was purchased from Sigma-Aldrich (St. Louis, MO, USA), dissolved in DMSO at a final concentration of $5 \mathrm{mg} / \mathrm{mL}$, and stored at $-20{ }^{\circ} \mathrm{C}$. Candida albicans ATCC 10231 (strain A), C. albicans ATCC 64124 (strain B), and C. albicans ATCC MYA-2876 (strain C) were kindly provided by Dr. Jon Y. Takemoto (Utah State University, Logan, UT, USA). C. albicans ATCC MYA-90819 (strain D), C. albicans ATCC MYA-2310 (strain E), C. albicans ATCC MYA-1237 (strain F), C. albicans ATCC MYA-1003 (strain G), Candida glabrata ATCC 2001 (strain H), Candida krusei ATCC 6258 (strain I), Candida parapsilosis ATCC 22019 (strain J), Aspergillus flavus ATCC MYA-3631 (strain K), and Aspergillus terreus ATCC MYA-3633 (strain M) were obtained from the American Type Culture Collection (ATCC; Manassas, VA, USA). Aspergillus nidulans ATCC 38163 (strain N) was received from Dr. Jon S. Thorson (University of Kentucky, Lexington, KY, USA). All clinical fungal isolates, C. glabrata (strain CG1-3), C. parapsilosis (strain CP1-3), and Cryptococcus neoformans (strain CN1-3) were obtained from Dr. Nathan P. Wiederhold (University of Texas Health Science Center, San Antonio, TX, USA). Filamentous fungi and yeasts were cultivated at $35{ }^{\circ} \mathrm{C}$ in RPMI 1640 medium (with L-glutamine, without sodium biocarbonate, Sigma-Aldrich, St. Louis, MO, USA) buffered to a pH of 7.0 with $0.165 \mathrm{M}$ morpholinepropanesulfonic acid (MOPS) buffer (Sigma-Aldrich).

The human bronchus normal cell line BEAS-2B (ATCC CRL-9609) and the human lung carcinoma cell line A549 (ATCC CRL-185) were kind gifts from the laboratories of Dr. David K. Orren (University of Kentucky, Lexington, KY, USA) and Dr. Markos Leggas (University of Kentucky, Lexington, KY, USA). The mammalian cells were grown in Dulbecco's Modified Eagle's Medium (DMEM) (from ATCC) with 10\% fetal bovine serum (FBS) (from ATCC) and 1\% Pen/Strep (from ATCC). The cell lines were incubated at $37^{\circ} \mathrm{C}$ and $5 \% \mathrm{CO}_{2}$ and passaged by trypsinization with $0.05 \%$ trypsin and $0.53 \mathrm{mM}$ EDTA (from ATCC). The cell confluency was determined by using a Nikon Eclipse TS100 microscope (Minato, Tokyo, Japan).

\subsection{Synthesis of Compounds $\mathbf{2}-\mathbf{1 6}$}

O-3-Deoxy-3-[[(1,1-dimethylethoxy)carbonyl]amino]-6-S-dodecyl-6-thio- $\alpha$-D-glucopyranosyl-(1 $\rightarrow 6)-O-$ [2,3,6-trideoxy-2,6-bis[[(1,1-dimethylethoxy)carbonyl]amino]- $\alpha$-D-ribo-hexopyranosyl-(1 $\rightarrow 4)]$-2-deoxy$N^{1}, N^{3}$-bis[(1,1-dimethylethoxy)carbonyl]-D-streptamine (2). A solution of compound 1 (0.30 g, $0.24 \mathrm{mmol}), \mathrm{Cs}_{2} \mathrm{CO}_{3}(0.12 \mathrm{~g}, 0.36 \mathrm{mmol})$, and 1-dodecanethiol $(0.29 \mathrm{~mL}, 1.22 \mathrm{mmol})$ in anhydrous DMF $(3 \mathrm{~mL})$ was stirred at room temperature overnight. Progress of the reaction was monitored by TLC (Hexanes:EtOAc/2:3, $\mathrm{R}_{f}$ 0.56). Purification by flash column chromatography $\left(\mathrm{SiO}_{2}\right.$, pure Hexanes to Hexanes:EtOAc/2:3) gave the known compound 2 [8] (0.18 g, 64\%) as a white solid: ${ }^{1} \mathrm{H}-\mathrm{NMR}$ (400 MHz, CD 3 OD, which matches the Reference [8], Figure S1) $\delta 5.07$ (br s, 1H, H-1'), 5.01 (br d, $J=2.8 \mathrm{~Hz}, 1 \mathrm{H},{\left.\mathrm{H}-1^{\prime \prime}\right)}^{\prime}, 4.05\left(\mathrm{ddd}, J_{1}=9.2 \mathrm{~Hz}, J_{2}=7.6 \mathrm{~Hz}, J_{3}=2.8 \mathrm{~Hz}, 1 \mathrm{H}, \mathrm{H}-5^{\prime \prime}\right), 3.70-3.30(\mathrm{~m}, 13 \mathrm{H}, \mathrm{H}-1$, H-3, H-4, H-5, H-6, H-2' ${ }^{\prime} \mathrm{H}-4^{\prime}, \mathrm{H}^{\prime} 5^{\prime}, \mathrm{H}-6^{\prime}(2 \mathrm{H}), \mathrm{H}-2^{\prime \prime}, \mathrm{H}-3^{\prime \prime}, \mathrm{H}-4^{\prime \prime}$ ), 2.97 (dd, $J_{1}=14.4 \mathrm{~Hz}, \mathrm{~J}_{2}=2.8 \mathrm{~Hz}$, $\left.1 \mathrm{H}, \mathrm{H}-6^{\prime \prime}\right), 2.61\left(\mathrm{~m}, 1 \mathrm{H}, \mathrm{H}-6^{\prime \prime}\right), 2.57\left(\mathrm{t}, J=7.2 \mathrm{~Hz}, 2 \mathrm{H}, \mathrm{SCH}_{2}\left(\mathrm{CH}_{2}\right)_{10} \mathrm{CH}_{3}\right), 2.14(\mathrm{~m}, 1 \mathrm{H}, \mathrm{H}-2 \mathrm{eq}), 1.99(\mathrm{~m}$, $1 \mathrm{H}, \mathrm{H}-3^{\prime} \mathrm{eq}$ ), 1.62 (app. q, $\left.J_{1}=J_{2}=J_{3}=12.0 \mathrm{~Hz}, 1 \mathrm{H}, \mathrm{H}-3^{\prime} \mathrm{ax}\right), 1.59-1.22\left(\mathrm{~m}, 66 \mathrm{H}, \mathrm{H}-2 \mathrm{ax}, 5 \times \mathrm{CO}_{2}\left(\mathrm{CH}_{3}\right)_{3}\right.$, $\left.\mathrm{SCH}_{2}\left(\mathrm{CH}_{2}\right)_{10} \mathrm{CH}_{3}\right), 0.88\left(\mathrm{t}, J=7.2 \mathrm{~Hz}, 3 \mathrm{H}, \mathrm{SCH}_{2}\left(\mathrm{CH}_{2}\right)_{10} \mathrm{CH}_{3}\right)$. 
O-3-Amino-3-deoxy-6-S-dodecyl-6-thio- $\alpha$-D-glucopyranosyl-(1 $\rightarrow 6)-O-[2,6$-diamino-2,3,6-trideoxy- $\alpha$ D-ribo-hexopyranosyl-(1 $\rightarrow 4)]$-2-deoxy-D-streptamine (3). Compound $2(26 \mathrm{mg}, 0.023 \mathrm{mmol})$ was treated at room temperature with neat TFA $(1 \mathrm{~mL})$ for $3 \mathrm{~min}$. The TFA was removed under reduced pressure, the residue was dissolved in a minimal volume of $\mathrm{H}_{2} \mathrm{O}$ and freeze-dried to afford the known compound 3 [8] (17 mg, 61\%) as a white powder: ${ }^{1} \mathrm{H}-\mathrm{NMR}\left(400 \mathrm{MHz}, \mathrm{D}_{2} \mathrm{O}\right.$, which matches Reference [8], Figure S2) $\delta 5.60\left(\mathrm{~d}, J=3.6 \mathrm{~Hz}, 1 \mathrm{H}, \mathrm{H}-1^{\prime}\right), 4.95\left(\mathrm{~d}, J=4.0 \mathrm{~Hz}, 1 \mathrm{H}, \mathrm{H}-1^{\prime \prime}\right), 3.90-3.77(\mathrm{~m}$, $4 \mathrm{H}, \mathrm{H}-4, \mathrm{H}-5^{\prime}, \mathrm{H}-2^{\prime \prime}, \mathrm{H}-5^{\prime \prime}$ ), 3.75 (app. t, $\left.J_{1}=J_{2}=9.2 \mathrm{~Hz}, 1 \mathrm{H}, \mathrm{H}-5\right), 3.65$ (app. t, $J_{1}=J_{2}=9.6 \mathrm{~Hz}$, 1H, H-6), 3.61-3.38 (m, 5H, H-1, H-3, H-2', H-4', H-4' ${ }^{\prime \prime}$ ), 3.32 (app. t, $J_{1}=J_{2}=10.8 \mathrm{~Hz}, 1 \mathrm{H}, \mathrm{H}-3^{\prime \prime}$ ), $3.29\left(\mathrm{dd}, J_{1}=13.6 \mathrm{~Hz}, J_{2}=3.6 \mathrm{~Hz}, 1 \mathrm{H}, \mathrm{H}-6^{\prime}\right), 3.13\left(\mathrm{dd}, J_{1}=14.0 \mathrm{~Hz}, J_{2}=7.2 \mathrm{~Hz}, 1 \mathrm{H}, \mathrm{H}-6^{\prime}\right), 2.91(\mathrm{dd}$, $\left.J_{1}=14.0 \mathrm{~Hz}, J_{2}=2.0 \mathrm{~Hz}, 1 \mathrm{H}, \mathrm{H}-6^{\prime \prime}\right), 2.63\left(\mathrm{dd}, J_{1}=14.0 \mathrm{~Hz}, J_{2}=8.0 \mathrm{~Hz}, 1 \mathrm{H}, \mathrm{H}-6^{\prime \prime}\right), 2.48(\mathrm{t}, J=7.6 \mathrm{~Hz}$, $\left.2 \mathrm{H}, \mathrm{SCH}_{2}\left(\mathrm{CH}_{2}\right)_{10} \mathrm{CH}_{3}\right), 2.42$ (app. dt, $J_{1}=12.4 \mathrm{~Hz}, J_{2}=J_{3}=4.4 \mathrm{~Hz}, 1 \mathrm{H}, \mathrm{H}-2 \mathrm{eq}$ ), 2.17 (app. dt, $J_{1}=12.4 \mathrm{~Hz}, J_{2}=J_{3}=4.4 \mathrm{~Hz}, 1 \mathrm{H}, \mathrm{H}-3^{\prime}$ eq), 1.88 (app. q, $J_{1}=J_{2}=J_{3}=12.0 \mathrm{~Hz}, 1 \mathrm{H}, \mathrm{H}-3^{\prime}$ ax), 1.80 (app. q, $\left.J_{1}=J_{2}=J_{3}=12.4 \mathrm{~Hz}, 1 \mathrm{H}, \mathrm{H}-2 \mathrm{ax}\right), 1.45\left(\mathrm{p}, J=7.2 \mathrm{~Hz}, 2 \mathrm{H}, \mathrm{SCH}_{2} \mathrm{CH}_{2}\left(\mathrm{CH}_{2}\right)_{9} \mathrm{CH}_{3}\right), 1.22-1.06(\mathrm{~m}, 18 \mathrm{H}$, $\left.\mathrm{SCH}_{2} \mathrm{CH}_{2}\left(\mathrm{CH}_{2}\right)_{9} \mathrm{CH}_{3}\right), 0.72\left(\mathrm{t}, J=7.2 \mathrm{~Hz}, 3 \mathrm{H}, \mathrm{SCH}_{2}\left(\mathrm{CH}_{2}\right)_{10} \mathrm{CH}_{3}\right)$.

O-3-Amino-3,6-dideoxy-6-(dodecylsulfonyl)- $\alpha$-D-glucopyranosyl-(1 $\rightarrow 6)-O-[2,6$-diamino-2,3,6-trideoxy$\alpha$-D-ribo-hexopyranosyl-( $1 \rightarrow 4)$ ]-2-deoxy-D-streptamine (4). $m$-Chloroperbenzoic acid ( $m$-CPBA, $30 \mathrm{mg}$, $0.17 \mathrm{mmol}$ ) was added to a solution of compound $2(56 \mathrm{mg}, 0.049 \mathrm{mmol})$ in $\mathrm{CHCl}_{3}(3 \mathrm{~mL})$ and the resulting mixture was stirred at room temperature for $16 \mathrm{~h}$. The reaction mixture was then diluted with $\mathrm{CHCl}_{3}(10 \mathrm{~mL})$ and washed with $1 \mathrm{M} \mathrm{KOH}(3 \times 2 \mathrm{~mL})$. The organic layers were dried over anhydrous $\mathrm{MgSO}_{4}$, filtered, and concentrated under reduced pressure. The crude product obtained was treated at room temperature with neat TFA $(0.5 \mathrm{~mL})$ for $3 \mathrm{~min}$. The TFA was removed under reduced pressure, the residue was dissolved in a minimal volume of $\mathrm{H}_{2} \mathrm{O}$ and freeze-dried to afford the known compound 4 [8] (40 mg, 66\%) as a white foam: ${ }^{1} \mathrm{H}-\mathrm{NMR}\left(400 \mathrm{MHz}, \mathrm{D}_{2} \mathrm{O}\right.$, which matches the Reference [8], Figure S3) $\delta 5.54\left(\mathrm{~d}, J=3.6 \mathrm{~Hz}, 1 \mathrm{H}, \mathrm{H}-1^{\prime}\right), 5.00\left(\mathrm{~d}, J=3.6 \mathrm{~Hz}, 1 \mathrm{H}, \mathrm{H}-1^{\prime \prime}\right), 4.30$ (app. t, $\left.J_{1}=J_{2}=9.6 \mathrm{~Hz}, 1 \mathrm{H}, \mathrm{H}-5^{\prime \prime}\right), 3.87-3.76\left(\mathrm{~m}, 4 \mathrm{H}, \mathrm{H}-4, \mathrm{H}-5, \mathrm{H}-5^{\prime}, \mathrm{H}-2^{\prime \prime}\right.$ ), 3.66 (app. t, $J_{1}=J_{2}=8.8 \mathrm{~Hz}, 1 \mathrm{H}$, $\mathrm{H}-6), 3.61-3.37$ (m, 8H, H-1, H-3, H-2' ${ }^{\prime} \mathrm{H}-4^{\prime}, \mathrm{H}-3^{\prime \prime}, \mathrm{H}-4^{\prime \prime}, \mathrm{H}-6^{\prime \prime}(2 \mathrm{H})$ ), 3.28 (dd, $J_{1}=13.6 \mathrm{~Hz}, J_{2}=3.6 \mathrm{~Hz}$, $\left.1 \mathrm{H}, \mathrm{H}-6^{\prime}\right), 3.19\left(\mathrm{t}, J=7.6 \mathrm{~Hz}, 2 \mathrm{H}, \mathrm{SO}_{2} \mathrm{C}_{2} \mathrm{CH}_{2} \mathrm{CH}_{2}\left(\mathrm{CH}_{2}\right)_{8} \mathrm{CH}_{3}\right), 3.11\left(\mathrm{dd}, J_{1}=13.6, J_{2}=7.2 \mathrm{~Hz}, 1 \mathrm{H}, \mathrm{H}-6^{\prime}\right)$, $2.42\left(\mathrm{dt}, J_{1}=12.4 \mathrm{~Hz}, J_{2}=J_{3}=4.4 \mathrm{~Hz}, 1 \mathrm{H}, \mathrm{H}-2 \mathrm{eq}\right), 2.16\left(\mathrm{dt}, J_{1}=12.4 \mathrm{~Hz}, J_{2}=J_{3}=4.4 \mathrm{~Hz}, 1 \mathrm{H}, \mathrm{H}-3^{\prime} \mathrm{eq}\right)$, 1.86 (app. q, $J_{1}=J_{2}=J_{3}=12.8 \mathrm{~Hz}, 1 \mathrm{H}, \mathrm{H}-3^{\prime} \mathrm{ax}$ ), 1.78 (app. q, $J_{1}=J_{2}=J_{3}=12.8 \mathrm{~Hz}, 1 \mathrm{H}, \mathrm{H}-2 \mathrm{ax}$ ), 1.66 (p, $\left.J=7.6 \mathrm{~Hz}, 2 \mathrm{H}, \mathrm{SO}_{2} \mathrm{CH}_{2} \mathrm{CH}_{2} \mathrm{CH}_{2}\left(\mathrm{CH}_{2}\right)_{8} \mathrm{CH}_{3}\right), 1.30\left(\mathrm{p}, J=7.6 \mathrm{~Hz}, 2 \mathrm{H}, \mathrm{SO}_{2} \mathrm{CH}_{2} \mathrm{CH}_{2} \mathrm{CH}_{2}\left(\mathrm{CH}_{2}\right)_{8} \mathrm{CH}_{3}\right)$, $1.13\left(\mathrm{~m}, 16 \mathrm{H}, \mathrm{SO}_{2} \mathrm{CH}_{2} \mathrm{CH}_{2} \mathrm{CH}_{2}\left(\mathrm{CH}_{2}\right)_{8} \mathrm{CH}_{3}\right), 0.71\left(\mathrm{t}, J=6.8 \mathrm{~Hz}, 3 \mathrm{H}, \mathrm{SO}_{2} \mathrm{CH}_{2} \mathrm{CH}_{2} \mathrm{CH}_{2}\left(\mathrm{CH}_{2}\right)_{8} \mathrm{CH}_{3}\right)$.

O-3,6-Dideoxy-3-[[(1,1-dimethylethoxy)carbonyl]amino]-6-(4-decyl-1H-1,2,3-triazol-1-yl)- $\alpha$-Dglucopyranosyl-( $1 \rightarrow 6)$-O-[2,3,6-trideoxy-2,6-bis[[(1,1-dimethylethoxy)carbonyl]amino]- $\alpha$-D-ribohexopyranosyl-(1 $\rightarrow 4)]$-2-deoxy- $N^{1}, N^{3}$-bis[(1,1-dimethylethoxy)carbonyl]-D-streptamine (6a). To a microwave reaction vessel, compound $5(60 \mathrm{mg}, 0.060 \mathrm{mmol})$, sodium L-ascorbate $(6 \mathrm{mg}, 0.030 \mathrm{mmol})$, $\mathrm{CuSO}_{4} \cdot 5 \mathrm{H}_{2} \mathrm{O}(6 \mathrm{mg}, 0.024 \mathrm{mmol}), 1$-dodecyne $(52 \mu \mathrm{L}, 0.24 \mathrm{mmol})$, and DMF $(1 \mathrm{~mL})$ were added. The reaction vessel was then sealed and irradiated by microwaves for $4 \mathrm{~min}$ at $80{ }^{\circ} \mathrm{C}$, twice. Progress of the reaction was monitored by TLC (Hexanes:EtOAc/3:7, $\mathrm{R}_{f} 0.49$ ). Upon completion, the reaction mixture was filtered through celite ${ }^{\circledR}$, and eluted with EtOAc. The filtrate was washed with $\mathrm{H}_{2} \mathrm{O}$ $(3 \times)$ and brine $(3 \times)$, dried over anhydrous $\mathrm{MgSO}_{4}$, filtered, and concentrated to give a crude product. Purification by column chromatography $\left(\mathrm{SiO}_{2}\right.$, pure Hexanes to Hexanes:EtOAc/2:3) gave compound 6a (40 mg, 57\%) as a white solid: ${ }^{1} \mathrm{H}-\mathrm{NMR}\left(400 \mathrm{MHz}, \mathrm{CD}_{3} \mathrm{OD}\right.$, Figure $\left.\mathrm{S} 4\right) \delta 7.73(\mathrm{~s}, 1 \mathrm{H}$, triazole ring), $5.09\left(\mathrm{~d}, J=2.8 \mathrm{~Hz}, 1 \mathrm{H}, \mathrm{H}-1^{\prime \prime}\right), 5.04\left(\mathrm{br} \mathrm{s}, 1 \mathrm{H}, \mathrm{H}-1^{\prime}\right), 4.67\left(\mathrm{br} \mathrm{d}, J=11.2 \mathrm{~Hz}, 1 \mathrm{H}, \mathrm{H}-6^{\prime \prime}\right)$, $4.55\left(\mathrm{t}, J=12.0 \mathrm{~Hz}, 1 \mathrm{H}, \mathrm{H}-6^{\prime \prime}\right), 4.39\left(\mathrm{~m}, 1 \mathrm{H}, \mathrm{H}-5^{\prime \prime}\right), 3.72\left(\mathrm{t}, J=10.0 \mathrm{~Hz}, 1 \mathrm{H}, \mathrm{H}-3^{\prime \prime}\right), 3.61-3.28(\mathrm{~m}, 11 \mathrm{H}$, H-1, H-3, H-4, H-5, H-6, H-2', H-4', H-5', H-6' (2H), H-2' $\left.{ }^{\prime \prime}\right), 2.96$ (t, J = 10.0 Hz, 1H, H-4' $), 2.66$ (t, $\left.J=7.6 \mathrm{~Hz}, 2 \mathrm{H}, \mathrm{CHN}_{3} \mathrm{CC}_{2} \mathrm{CH}_{2}\left(\mathrm{CH}_{2}\right)_{7} \mathrm{CH}_{3}\right), 2.01$ (m, 2H, H-2eq, H-3'eq), 1.69-1.57 (m, 3H, H-3' ax, $\left.\mathrm{CHN}_{3} \mathrm{CCH}_{2} \mathrm{CH}_{2}\left(\mathrm{CH}_{2}\right)_{7} \mathrm{CH}_{3}\right), 1.44-1.27\left(\mathrm{~m}, 60 \mathrm{H}, \mathrm{H}-2 \mathrm{ax}, 5 \times \mathrm{CO}_{2}\left(\mathrm{CH}_{3}\right)_{3}, \mathrm{CHN}_{3} \mathrm{CCH}_{2} \mathrm{CH}_{2}\left(\mathrm{CH}_{2}\right)_{7} \mathrm{CH}_{3}\right)$, $0.88\left(\mathrm{t}, J=7.2 \mathrm{~Hz}, 3 \mathrm{H}, \mathrm{CHN}_{3} \mathrm{CCH}_{2} \mathrm{CH}_{2}\left(\mathrm{CH}_{2}\right)_{7} \mathrm{CH}_{3}\right) ;{ }^{13} \mathrm{C}-\mathrm{NMR}\left(100 \mathrm{MHz}, \mathrm{CD}_{3} \mathrm{OD}\right.$, Figure S5) $\delta$ 158.0, 157.8, 156.4, 156.3 (2 carbons), 147.6, 123.2, 98.4, 97.3, 81.6, 80.3, 79.3, 79.0 (2 carbons), 78.9, 78.7, 75.1, 
72.1, 70.4, 70.2, 69.0, 65.0, 55.6, 50.3, 50.2, 49.8, 40.6, 34.6 (2 carbons), 32.9, 31.6, 29.32, 29.30, 29.2, 29.1, 29.0, 28.9, 27.4 (15 carbons), 24.9, 22.3, 13.0; HR-MS (Figure S6) calcd for $\mathrm{C}_{55} \mathrm{H}_{99} \mathrm{~N}_{8} \mathrm{O}_{18}[\mathrm{M}+\mathrm{H}]^{+}$ 1159.7072; found 1159.7096.

O-3,6-Dideoxy-3-[[(1,1-dimethylethoxy)carbonyl]amino]-6-(4-dodecyl-1H-1,2,3-triazol-1-yl)- $\alpha$-Dglucopyranosyl-(1 $\rightarrow 6)-O-[2,3,6$-trideoxy-2,6-bis[[(1,1-dimethylethoxy)carbonyl]amino]- $\alpha$-D-ribohexopyranosyl-(1 $\rightarrow 4)]$-2-deoxy- $N^{1}, N^{3}$-bis[(1,1-dimethylethoxy)carbonyl]-D-streptamine $(6 \mathbf{b})$. To a microwave reaction vessel, compound $5(60 \mathrm{mg}, 0.060 \mathrm{mmol})$, sodium L-ascorbate $(6 \mathrm{mg}, 0.030 \mathrm{mmol})$, $\mathrm{CuSO}_{4} \cdot 5 \mathrm{H}_{2} \mathrm{O}(6 \mathrm{mg}, 0.024 \mathrm{mmol})$, 1-tetradecyne $(66 \mu \mathrm{L}, 0.24 \mathrm{mmol})$, and DMF $(1 \mathrm{~mL})$ were added. The reaction vessel was then sealed and irradiated by microwaves for $4 \mathrm{~min}$ at $80{ }^{\circ} \mathrm{C}$, twice. Progress of the reaction was monitored by TLC (Hexanes:EtOAc/3:7, $\mathrm{R}_{f} 0.58$ ). Upon completion, the reaction mixture was filtered through celite ${ }^{\circledR}$, and eluted with EtOAc. The filtrate was washed with $\mathrm{H}_{2} \mathrm{O}(3 \times)$ and brine $(3 \times)$, dried over anhydrous $\mathrm{MgSO}_{4}$, filtered, and concentrated to give a crude product. Purification by column chromatography $\left(\mathrm{SiO}_{2}\right.$, pure Hexanes to Hexanes:EtOAc/2:3) gave the known compound 6b [11] (45 mg, 63\%) as a white solid: ${ }^{1} \mathrm{H}-\mathrm{NMR}$ (400 $\mathrm{MHz}, \mathrm{CD}_{3} \mathrm{OD}$, which matches the Reference [11], Figure S7) $\delta 7.73$ (s, 1H, triazole ring), 5.09 (br s, 1H, H-1' $), 5.03$ (br s, 1H, H-1'), 4.66 (br $\left.\mathrm{d}, J=10.4 \mathrm{~Hz}, 1 \mathrm{H}, \mathrm{H}-6^{\prime \prime}\right), 4.55\left(\mathrm{t}, J=14.4 \mathrm{~Hz}, 1 \mathrm{H}, \mathrm{H}-6^{\prime \prime}\right), 4.40\left(\mathrm{~m}, 1 \mathrm{H}, \mathrm{H}-5^{\prime \prime}\right), 3.72(\mathrm{t}, J=10.8 \mathrm{~Hz}$, $1 \mathrm{H}, \mathrm{H}-3^{\prime \prime}$ ), 3.61-3.24 (m, 11H, H-1, H-3, H-4, H-5, H-6, H-2' , H-4', H-5', H-6' (2H), H-2"'), 2.96 (t, $\left.J=10.8 \mathrm{~Hz}, 1 \mathrm{H}, \mathrm{H}_{-} 4^{\prime \prime}\right), 2.66\left(\mathrm{t}, J=7.2 \mathrm{~Hz}, 2 \mathrm{H}, \mathrm{CHN}_{3} \mathrm{CC}_{2} \mathrm{CH}_{2}\left(\mathrm{CH}_{2}\right)_{9} \mathrm{CH}_{3}\right), 2.01\left(\mathrm{~m}, 2 \mathrm{H}, \mathrm{H}-2 \mathrm{eq}, \mathrm{H}-3^{\prime} \mathrm{eq}\right)$, 1.69-1.57 (m, 3H, H-3' ax, $\left.\mathrm{CHN}_{3} \mathrm{CCH}_{2} \mathrm{CH}_{2}\left(\mathrm{CH}_{2}\right)_{9} \mathrm{CH}_{3}\right), 1.44-1.27$ (m, 64H, H-2ax, 5× $\mathrm{CO}_{2}\left(\mathrm{CH}_{3}\right)_{3}$, $\left.\mathrm{CHN}_{3} \mathrm{CCH}_{2} \mathrm{CH}_{2}\left(\mathrm{CH}_{2}\right)_{9} \mathrm{CH}_{3}\right), 0.88\left(\mathrm{t}, J=7.6 \mathrm{~Hz}, 3 \mathrm{H}, \mathrm{CHN}_{3} \mathrm{CCH}_{2} \mathrm{CH}_{2}\left(\mathrm{CH}_{2}\right)_{9} \mathrm{CH}_{3}\right)$.

O-3-Amino-3,6-dideoxy-6-(4-decyl-1H-1,2,3-triazol-1-yl)- $\alpha$-D-glucopyranosyl-(1 $\rightarrow 6)-O-[2,6$-diamino2,3,6-trideoxy- $\alpha$-D-ribo-hexopyranosyl-(1 $\rightarrow 4)]$-2-deoxy-D-streptamine (7a). Compound $6 \mathbf{a}(30 \mathrm{mg}$, $0.026 \mathrm{mmol})$ was treated at room temperature with neat TFA $(1 \mathrm{~mL})$ for $3 \mathrm{~min}$. The TFA was removed under reduced pressure, the residue was dissolved in a minimal volume of $\mathrm{H}_{2} \mathrm{O}$, extracted with $\mathrm{CH}_{2} \mathrm{Cl}_{2}(3 \times)$, and freeze-dried to afford compound $7 \mathrm{a}(30 \mathrm{mg}, 94 \%)$ as a white powder: ${ }^{1} \mathrm{H}-\mathrm{NMR}$ $\left(400 \mathrm{MHz}, \mathrm{D}_{2} \mathrm{O}\right.$, Figure S8) $\delta 7.62\left(\mathrm{~s}, 1 \mathrm{H}\right.$, triazole ring), $5.64\left(\mathrm{~d}, J=3.6 \mathrm{~Hz}, 1 \mathrm{H}, \mathrm{H}-1^{\prime}\right), 4.88(\mathrm{~d}, J=3.6 \mathrm{~Hz}$, $\left.1 \mathrm{H}, \mathrm{H}-1^{\prime \prime}\right), 4.58\left(\mathrm{~m}, 1 \mathrm{H}, \mathrm{H}-6^{\prime \prime}\right), 4.44\left(\mathrm{dd}, J_{1}=14.8 \mathrm{~Hz}, J_{2}=7.2 \mathrm{~Hz}, 1 \mathrm{H}, \mathrm{H}-6^{\prime \prime}\right), 4.18\left(\mathrm{~m}, 1 \mathrm{H}, \mathrm{H}-5^{\prime \prime}\right)$, 3.81-3.68 (m, 3H, H-4, H-5' , H-2' $)$, 3.64-3.50 (m, 4H, H-5, H-6, H-2' , H-4' ), 3.44-3.30 (m, 4H, H-1, H-3, $\left.\mathrm{H}-3^{\prime \prime}, \mathrm{H}-4^{\prime \prime}\right), 3.27\left(\mathrm{dd}, J_{1}=13.6 \mathrm{~Hz}, J_{2}=3.6 \mathrm{~Hz}, 1 \mathrm{H}, \mathrm{H}-6^{\prime}\right), 3.07\left(\mathrm{dd}, J_{1}=14.0 \mathrm{~Hz}, J_{2}=7.6 \mathrm{~Hz}, 1 \mathrm{H}, \mathrm{H}-6^{\prime}\right)$, $2.51\left(\mathrm{t}, J=7.2 \mathrm{~Hz}, 2 \mathrm{H}, \mathrm{CHN}_{3} \mathrm{CCH}_{2} \mathrm{CH}_{2}\left(\mathrm{CH}_{2}\right)_{7} \mathrm{CH}_{3}\right), 2.36\left(\mathrm{dt}, J_{1}=12.8 \mathrm{~Hz}, J_{2}=J_{3}=3.6 \mathrm{~Hz}, 1 \mathrm{H}, \mathrm{H}-2 \mathrm{eq}\right)$, $2.16\left(\mathrm{dt}, J_{1}=12.4 \mathrm{~Hz}, J_{2}=J_{3}=4.4 \mathrm{~Hz}, 1 \mathrm{H}, \mathrm{H}-3^{\prime} \mathrm{eq}\right), 1.87\left(\operatorname{app} . \mathrm{q}, J_{1}=J_{2}=J_{3}=12.0 \mathrm{~Hz}, 1 \mathrm{H}, \mathrm{H}-3^{\prime} \mathrm{ax}\right)$, 1.74 (app. q, $\left.J_{1}=J_{2}=J_{3}=12.8 \mathrm{~Hz}, 1 \mathrm{H}, \mathrm{H}-2 \mathrm{ax}\right), 1.45\left(\mathrm{p}, J=6.4 \mathrm{~Hz}, 2 \mathrm{H}, \mathrm{CHN}_{3} \mathrm{CCH}_{2} \mathrm{CH}_{2}\left(\mathrm{CH}_{2}\right)_{7} \mathrm{CH}_{3}\right)$ 1.20-1.00 (m, 14H, $\left.\mathrm{CHN}_{3} \mathrm{CCH}_{2} \mathrm{CH}_{2}\left(\mathrm{CH}_{2}\right)_{7} \mathrm{CH}_{3}\right), 0.67\left(\mathrm{t}, \mathrm{J}=6.8 \mathrm{~Hz}, 3 \mathrm{H}, \mathrm{CHN}_{3} \mathrm{CCH}_{2} \mathrm{CH}_{2}\left(\mathrm{CH}_{2}\right)_{7} \mathrm{CH}_{3}\right)$; ${ }^{13} \mathrm{C}-\mathrm{NMR}\left(100 \mathrm{MHz}, \mathrm{D}_{2} \mathrm{O}\right.$, Figure S9) $\delta 148.6,125.0,100.8,93.8,83.9,76.6,74.2,70.8,69.9,67.7,66.5$, 64.4, 54.6, 50.2, 49.5, 48.2, 47.7, 39.8, 31.1, 29.3, 28.54, 28.47, 28.4, 28.3, 28.2, 27.9, 27.6, 24.3, 21.9, 13.3; HR-MS (Figure S10) calcd for $\mathrm{C}_{30} \mathrm{H}_{59} \mathrm{~N}_{8} \mathrm{O}_{8}[\mathrm{M}+\mathrm{H}]^{+}$659.4450; found 659.4457.

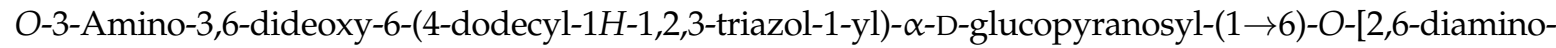
2,3,6-trideoxy- $\alpha$-D-ribo-hexopyranosyl-(1 $\rightarrow 4)]$-2-deoxy-D-streptamine (7b). Compound $6 \mathbf{b}(35 \mathrm{mg}$, $0.029 \mathrm{mmol})$ was treated at room temperature with neat TFA $(1 \mathrm{~mL})$ for $3 \mathrm{~min}$. The TFA was removed under reduced pressure, the residue was dissolved in a minimal volume of $\mathrm{H}_{2} \mathrm{O}$, extracted with $\mathrm{CH}_{2} \mathrm{Cl}_{2}(3 \times)$, and freeze-dried to afford the known compound $7 \mathbf{b}$ [11] (38 mg, quant.) as a white powder: ${ }^{1} \mathrm{H}-\mathrm{NMR}\left(400 \mathrm{MHz}, \mathrm{D}_{2} \mathrm{O}\right.$, which matches Reference [11], Figure S11) $\delta 7.62(\mathrm{~s}, 1 \mathrm{H}$, triazole ring), $5.64\left(\mathrm{~d}, J=3.6 \mathrm{~Hz}, 1 \mathrm{H}, \mathrm{H}-1^{\prime}\right), 4.88\left(\mathrm{~d}, J=3.6 \mathrm{~Hz}, 1 \mathrm{H}, \mathrm{H}-1^{\prime \prime}\right), 4.63\left(\mathrm{~m}, 1 \mathrm{H}, \mathrm{H}-6^{\prime \prime}\right), 4.44(\mathrm{dd}$, $\left.J_{1}=14.8 \mathrm{~Hz}, J_{2}=7.2 \mathrm{~Hz}, 1 \mathrm{H}, \mathrm{H}-6^{\prime \prime}\right), 4.18\left(\mathrm{~m}, 1 \mathrm{H}, \mathrm{H}-5^{\prime \prime}\right), 3.80-3.69$ (m, 3H, H-4, H-5' , H-2 $\left.{ }^{\prime \prime}\right), 3.64-3.50$ (m, $\left.4 \mathrm{H}, \mathrm{H}-5, \mathrm{H}-6, \mathrm{H}-2^{\prime}, \mathrm{H}-4^{\prime}\right), 3.42-3.30\left(\mathrm{~m}, 4 \mathrm{H}, \mathrm{H}-1, \mathrm{H}-3, \mathrm{H}-3^{\prime \prime}{ }^{\prime}, \mathrm{H}-4^{\prime \prime}\right), 3.27\left(\mathrm{dd}, J_{1}=13.6 \mathrm{~Hz}, \mathrm{~J}_{2}=2.8 \mathrm{~Hz}, 1 \mathrm{H}\right.$, H-6 $\left.{ }^{\prime}\right), 3.07\left(\mathrm{dd}, J_{1}=13.6 \mathrm{~Hz}, J_{2}=7.6 \mathrm{~Hz}, 1 \mathrm{H}, \mathrm{H}-6^{\prime}\right), 2.51\left(\mathrm{t}, J=7.2 \mathrm{~Hz}, 2 \mathrm{H}, \mathrm{CHN}_{3} \mathrm{CCH}_{2} \mathrm{CH}_{2}\left(\mathrm{CH}_{2}\right)_{9} \mathrm{CH}_{3}\right)$, $2.36\left(\mathrm{dt}, J_{1}=12.8 \mathrm{~Hz}, J_{2}=J_{3}=4.4 \mathrm{~Hz}, 1 \mathrm{H}, \mathrm{H}-2 \mathrm{eq}\right), 2.16\left(\mathrm{dt}, J_{1}=12.4 \mathrm{~Hz}, J_{2}=J_{3}=4.4 \mathrm{~Hz}, 1 \mathrm{H}, \mathrm{H}-3^{\prime} \mathrm{eq}\right)$, 1.87 (app. q, $J_{1}=J_{2}=J_{3}=12.0 \mathrm{~Hz}, 1 \mathrm{H}, \mathrm{H}-3^{\prime}$ ax), 1.74 (app. q, $\left.J_{1}=J_{2}=J_{3}=12.4 \mathrm{~Hz}, 1 \mathrm{H}, \mathrm{H}-2 \mathrm{ax}\right), 1.45(\mathrm{p}$, 
$\left.J=6.4 \mathrm{~Hz}, 2 \mathrm{H}, \mathrm{CHN}_{3} \mathrm{CCH}_{2} \mathrm{CH}_{2}\left(\mathrm{CH}_{2}\right)_{9} \mathrm{CH}_{3}\right) 1.20-1.00\left(\mathrm{~m}, 18 \mathrm{H}, \mathrm{CHN}_{3} \mathrm{CCH}_{2} \mathrm{CH}_{2}\left(\mathrm{CH}_{2}\right)_{9} \mathrm{CH}_{3}\right), 0.67(\mathrm{t}$, $\left.J=6.8 \mathrm{~Hz}, 3 \mathrm{H}, \mathrm{CHN}_{3} \mathrm{CCH}_{2} \mathrm{CH}_{2}\left(\mathrm{CH}_{2}\right)_{9} \mathrm{CH}_{3}\right)$.

O-3,6-Dideoxy-3-[[(1,1-dimethylethoxy)carbonyl]amino]-6-[(1-oxododecyl)amino]- $\alpha$-D-glucopyranosyl$(1 \rightarrow 6)$-O-[2,3,6-trideoxy-2,6-bis[[(1,1-dimethylethoxy)carbonyl]amino]- $\alpha$-D-ribo-hexopyranosyl-( $1 \rightarrow 4)]-$ 2-deoxy- $N^{1}, N^{3}$-bis[(1,1-dimethylethoxy)carbonyl]-D-streptamine (8). A solution of compound 7 $(80 \mathrm{mg}, 0.081 \mathrm{mmol})$ in THF $(2 \mathrm{~mL})$ and $\mathrm{H}_{2} \mathrm{O}(0.1 \mathrm{~mL})$ was treated with $1 \mathrm{M} \mathrm{PMe}_{3}$ in THF $(0.11 \mathrm{~mL}$, $0.11 \mathrm{mmol}$ ) and the resulting mixture was stirred at $50{ }^{\circ} \mathrm{C}$ for $1 \mathrm{~h}$. Progress of the reaction was monitored by TLC $\left(\mathrm{CH}_{2} \mathrm{Cl}_{2}: \mathrm{MeOH} / 9: 1+\mathrm{NH}_{4} \mathrm{OH}(0.7 \%), \mathrm{R}_{f}\right.$ 0.25). Upon completion, the solvents were removed and the crude material obtained was filtered through silica gel, eluting with Hexanes:EtOAc/1:3 and $\mathrm{CH}_{2} \mathrm{Cl}_{2}: \mathrm{MeOH} / 9: 1+\mathrm{NH}_{4} \mathrm{OH}(0.7 \%)$. The filtrate collected from the latter eluting solvent was concentrated, redissolved in anhydrous DMF, and added to a pre-stirred, ice-cooled solution of lauric acid (32 mg, $0.16 \mathrm{mmol}), \mathrm{EDC} \cdot \mathrm{HCl}(39 \mathrm{mg}, 0.20 \mathrm{mmol}), \mathrm{HOBt}(31 \mathrm{mg}$, $0.20 \mathrm{mmol})$, DIPEA $(0.11 \mathrm{~mL}, 0.64 \mathrm{mmol})$, and anhydrous DMF $(2 \mathrm{~mL})$. The resulting mixture was stirred overnight till room temperature. Progress of the reaction was monitored by TLC (Hexanes:EtOAc/2:3, $\mathrm{R}_{f}$ 0.24). Upon completion, the reaction mixture was diluted with $\mathrm{H}_{2} \mathrm{O}$ and extracted with EtOAc $(3 \times)$. The combined organic layers were washed with $\mathrm{H}_{2} \mathrm{O}(3 \times)$ and brine $(3 \times)$, dried over anhydrous $\mathrm{MgSO}_{4}$, filtered, and concentrated to give a crude product. Purification by flash column chromatography $\left(\mathrm{SiO}_{2}\right.$, pure Hexanes to Hexanes:EtOAc/2:3) gave compound 8 (51 mg, 55\%) as a white solid: ${ }^{1} \mathrm{H}-\mathrm{NMR}\left(400 \mathrm{MHz}, \mathrm{CD}_{3} \mathrm{OD}\right.$, Figure S12) $\delta 5.11$ (br s, $\left.1 \mathrm{H}, \mathrm{H}-1^{\prime}\right)$, $5.01\left(\mathrm{~d}, J=3.2 \mathrm{~Hz}, 1 \mathrm{H}, \mathrm{H}-1^{\prime \prime}\right), 4.01\left(\mathrm{~m}, 1 \mathrm{H}, \mathrm{H}-5^{\prime \prime}\right), 3.66-3.28$ (m, 14H, H-1, H-3, H-4, H-5, H-6, H-2', $\left.\mathrm{H}-4^{\prime}, \mathrm{H}-5^{\prime}, \mathrm{H}-6^{\prime}(2 \mathrm{H}), \mathrm{H}-2^{\prime \prime}, \mathrm{H}-3^{\prime \prime}, \mathrm{H}-6^{\prime \prime}(2 \mathrm{H})\right), 3.14\left(\mathrm{t}, J=9.6 \mathrm{~Hz}, 1 \mathrm{H}, \mathrm{H}-4^{\prime \prime}\right), 2.19(\mathrm{t}, J=7.2 \mathrm{~Hz}$, $\left.2 \mathrm{H}, \mathrm{NHCOCH}_{2}\left(\mathrm{CH}_{2}\right)_{9} \mathrm{CH}_{3}\right), 2.10-1.90\left(\mathrm{~m}, 2 \mathrm{H}, \mathrm{H}-2 \mathrm{eq}, \mathrm{H}-3^{\prime}\right.$ eq) $1.70-1.20$ (m, 65H, H-2ax, H-3'ax, $\left.5 \times \mathrm{CO}_{2}\left(\mathrm{CH}_{3}\right)_{3}, \mathrm{NHCOCH}_{2}\left(\mathrm{CH}_{2}\right)_{9} \mathrm{CH}_{3}\right), 0.88\left(\mathrm{t}, J=7.2 \mathrm{~Hz}, 3 \mathrm{H}, \mathrm{NHCOCH}_{2}\left(\mathrm{CH}_{2}\right)_{9} \mathrm{CH}_{3}\right) ;{ }^{13} \mathrm{C}-\mathrm{NMR}$ $\left(100 \mathrm{MHz}, \mathrm{CD}_{3} \mathrm{OD}\right.$, Figure S13) $\delta$ 175.6, 157.9, 157.8, 156.6, 156.33, 156.25, 98.4, 98.0, 81.8, 81.1, 79.3, 79.1, 78.9 ( 2 carbons), 78.7, 75.5, 72.0, 71.2, 70.7, 69.3, 65.1, 55.6, 50.3, 49.7, 49.5, 40.6, 40.1, 35.7, 34.4, 32.9, 31.7, 29.4, 29.34, 29.26, 29.1, 29.0, 28.4, 27.4 (15 carbons), 25.6, 22.3, 13.0; HR-MS (Figure S14) calcd for $\mathrm{C}_{55} \mathrm{H}_{101} \mathrm{~N}_{6} \mathrm{O}_{19}[\mathrm{M}+\mathrm{H}]^{+}$1149.7116; found 1149.7128 .

O-3-Amino-3,6-dideoxy-6-[(1-oxododecyl)amino]- $\alpha$-D-glucopyranosyl-(1 $\rightarrow 6)-O-[2,6-d i a m i n o-2,3,6-$ trideoxy- $\alpha$-D-ribo-hexopyranosyl-(1 $\rightarrow 4)$ ]-2-deoxy-D-streptamine (9). Compound 8 ( $41 \mathrm{mg}, 0.036 \mathrm{mmol})$ was treated at room temperature with neat TFA $(1 \mathrm{~mL})$ for $3 \mathrm{~min}$. The TFA was removed under reduced pressure, the residue was dissolved in a minimal volume of $\mathrm{H}_{2} \mathrm{O}$, extracted with $\mathrm{CH}_{2} \mathrm{Cl}_{2}(3 \times)$, and freeze-dried to afford compound $9(40 \mathrm{mg}, 93 \%)$ as a white powder: ${ }^{1} \mathrm{H}-\mathrm{NMR}\left(400 \mathrm{MHz}, \mathrm{D}_{2} \mathrm{O}\right.$, Figure S15) $\delta 5.63\left(\mathrm{~d}, J=3.6 \mathrm{~Hz}, 1 \mathrm{H}, \mathrm{H}-1^{\prime}\right), 4.88\left(\mathrm{~d}, J=4.0 \mathrm{~Hz}, 1 \mathrm{H}, \mathrm{H}-1^{\prime \prime}\right), 3.84-3.71\left(\mathrm{~m}, 4 \mathrm{H}, \mathrm{H}-4, \mathrm{H}-5^{\prime}\right.$, H-2 $\left.{ }^{\prime \prime}, \mathrm{H}-5^{\prime \prime}\right), 3.66$ (t, $\left.J=9.6 \mathrm{~Hz}, 1 \mathrm{H}, \mathrm{H}-5\right), 3.61-3.23$ (m, 10H, H-1, H-3, H-6, H-2' , H-4' , H-6', H-3' $\left.\mathrm{H}-4^{\prime \prime}, \mathrm{H}-6^{\prime \prime}(2 \mathrm{H})\right), 3.09\left(\mathrm{dd}, J_{1}=13.6 \mathrm{~Hz}, J_{2}=6.8 \mathrm{~Hz}, 1 \mathrm{H}, \mathrm{H}-6^{\prime}\right), 2.37\left(\mathrm{dt}, J_{1}=12.4 \mathrm{~Hz}, J_{2}=J_{3}=4.4 \mathrm{~Hz}\right.$, 1H, H-2eq), $2.13\left(\mathrm{~m}, 1 \mathrm{H}, \mathrm{H}-3^{\prime} \mathrm{eq}\right), 2.09\left(\mathrm{t}, J=8.0 \mathrm{~Hz}, 2 \mathrm{H}, \mathrm{NHCOC} \underline{\mathrm{H}}_{2} \mathrm{CH}_{2}\left(\mathrm{CH}_{2}\right)_{8} \mathrm{CH}_{3}\right), 1.85$ (app. q, $J_{1}=J_{2}=J_{3}=12.0 \mathrm{~Hz}, 1 \mathrm{H}, \mathrm{H}-3^{\prime} \mathrm{ax}$ ), 1.76 (app. q, $\left.J_{1}=J_{2}=J_{3}=12.8 \mathrm{~Hz}, 1 \mathrm{H}, \mathrm{H}-2 \mathrm{ax}\right), 1.40(\mathrm{p}, J=6.0 \mathrm{~Hz}$, $\left.2 \mathrm{H}, \mathrm{NHCOCH}_{2} \mathrm{CH}_{2}\left(\mathrm{CH}_{2}\right)_{8} \mathrm{CH}_{3}\right), 1.09\left(\mathrm{~m}, 16 \mathrm{H}, \mathrm{NHCOCH}_{2} \mathrm{CH}_{2}\left(\mathrm{CH}_{2}\right)_{8} \mathrm{CH}_{3}\right), 0.67(\mathrm{t}, J=6.8 \mathrm{~Hz}, 3 \mathrm{H}$, $\left.\mathrm{NHCOCH}_{2} \mathrm{CH}_{2}\left(\mathrm{CH}_{2}\right)_{8} \mathrm{CH}_{3}\right) ;{ }^{13} \mathrm{C}-\mathrm{NMR}\left(100 \mathrm{MHz}, \mathrm{D}_{2} \mathrm{O}\right.$, Figure S16) $\delta 178.1,100.8,94.0,83.5,77.2$, 74.1, 70.9, 70.2, 68.0, 66.4, 64.3, 54.5, 49.6, 48.2, 47.6, 39.7, 38.8, 35.7, 31.1, 29.2, 28.6 (2 carbons), 28.5, 28.4, 28.24, 28.16, 27.7, 25.3, 21.9, 13.3; HR-MS (Figure S17) calcd for $\mathrm{C}_{30} \mathrm{H}_{60} \mathrm{~N}_{6} \mathrm{O}_{9}[\mathrm{M}+\mathrm{H}]^{+}$649.4495; found 649.4494 .

O-3-Azido-3-deoxy- $\alpha$-D-glucopyranosyl-( $1 \rightarrow 6)$-O-[2,6-diazido-2,3,6-trideoxy- $\alpha$-D-ribo-hexopyranosyl$(1 \rightarrow 4)]-1,3-$ diazido-1,2,3-trideoxy-D-myo-inositol (10). The synthesis started with the preparation of triflic azide $\left(\mathrm{TfN}_{3}\right)$. Note: extreme caution should be exercised while handling azides! A solution of $\mathrm{NaN}_{3}(8.34 \mathrm{~g}, 128.3 \mathrm{mmol})$ in $\mathrm{H}_{2} \mathrm{O}(25 \mathrm{~mL})$ was cooled down to $0{ }^{\circ} \mathrm{C}$ in an ice- $\mathrm{H}_{2} \mathrm{O}$ bath and vigorously stirred. $\mathrm{CH}_{2} \mathrm{Cl}_{2}(25 \mathrm{~mL})$ was added, followed by $\mathrm{Tf}_{2} \mathrm{O}(10.8 \mathrm{~mL}, 64.2 \mathrm{mmol})$, and the resulting mixture was stirred for $2 \mathrm{~h}$ at $0{ }^{\circ} \mathrm{C} .30$ min before completion of the $\mathrm{TfN}_{3}$ reaction, tobramycin $(2.0 \mathrm{~g}$, $4.28 \mathrm{mmol})$ and $\mathrm{ZnCl}_{2}(29 \mathrm{mg}, 0.21 \mathrm{mmol})$ were dissolved in $\mathrm{H}_{2} \mathrm{O}(65 \mathrm{~mL})$. $\mathrm{Et}_{3} \mathrm{~N}(8.9 \mathrm{~mL}, 64.2 \mathrm{mmol})$ 
was added, followed by dropwise addition of $\mathrm{MeOH}(215 \mathrm{~mL})$. The resulting mixture was stirred at room temperature. Meanwhile, saturated aqueous $\mathrm{NaHCO}_{3}$ was carefully added to the stirred solution of $\mathrm{TfN}_{3}$ until the reaction mixture stopped fizzing. The $\mathrm{TfN}_{3}$ mixture was then extracted with $\mathrm{CH}_{2} \mathrm{Cl}_{2}(2 \times 20 \mathrm{~mL})$, and the combined $\mathrm{CH}_{2} \mathrm{Cl}_{2}$ solutions of $\mathrm{TfN}_{3}$ were washed again with saturated $\mathrm{NaHCO}_{3}$, and filtered directly into the tobramycin solution. The resulting mixture was vigorously stirred for $3 \mathrm{~h}$. The reaction was quenched by addition of solid $\mathrm{NaHCO}_{3}$, filtered through a bed of celite $^{\circledR}$, and the filtrate was dried in vacuo. Purification by flash column chromatography $\left(\mathrm{SiO}_{2}\right.$, pure $\mathrm{CH}_{2} \mathrm{Cl}_{2}$ to $\mathrm{CH}_{2} \mathrm{Cl}_{2}: \mathrm{MeOH} / 19: 1, \mathrm{R}_{f} 0.29$ in $\left.\mathrm{CH}_{2} \mathrm{Cl}_{2}: \mathrm{MeOH} / 19: 1\right)$ gave the known compound 10 [45] ( $2.4 \mathrm{~g}, 92 \%)$ as a white solid: ${ }^{1} \mathrm{H}-\mathrm{NMR}\left(400 \mathrm{MHz}, \mathrm{CD}_{3} \mathrm{OD}\right.$, which matches Reference [45], Figure S18) $\delta 5.58\left(\mathrm{~d}, J=3.2 \mathrm{~Hz}, 1 \mathrm{H}, \mathrm{H}-1^{\prime}\right), 5.23\left(\mathrm{~d}, J=3.6 \mathrm{~Hz}, 1 \mathrm{H}, \mathrm{H}-1^{\prime \prime}\right), 4.08\left(\mathrm{ddd}, J_{1}=9.2 \mathrm{~Hz}, J_{2}=5.6 \mathrm{~Hz}\right.$, $\left.J_{3}=2.4 \mathrm{~Hz}, 1 \mathrm{H}\right), 4.02\left(\mathrm{ddd}, J_{1}=9.6 \mathrm{~Hz}, J_{2}=4.4 \mathrm{~Hz}, J_{3}=2.4 \mathrm{~Hz}, 1 \mathrm{H}\right), 3.76\left(\mathrm{dd}, J_{1}=12.0 \mathrm{~Hz}, J_{2}=2.4 \mathrm{~Hz}\right.$, $1 \mathrm{H}), 3.68-3.29(\mathrm{~m}, 10 \mathrm{H}), 3.21-3.15(\mathrm{~m}, 3 \mathrm{H}), 2.37\left(\mathrm{dt}, J_{1}=12.4 \mathrm{~Hz}, J_{2}=J_{3}=4.4 \mathrm{~Hz}, 1 \mathrm{H}, \mathrm{H}-2 \mathrm{eq}\right), 2.13(\mathrm{dt}$, $\left.J_{1}=11.2 \mathrm{~Hz}, J_{2}=J_{3}=4.4 \mathrm{~Hz}, 1 \mathrm{H}, \mathrm{H}-3^{\prime} \mathrm{eq}\right), 1.99$ (app. q, $\left.J_{1}=J_{2}=J_{3}=11.2 \mathrm{~Hz}, 1 \mathrm{H}, \mathrm{H}-3^{\prime} \mathrm{ax}\right), 1.55$ (app. q, $\left.J_{1}=J_{2}=J_{3}=12.0 \mathrm{~Hz}, 1 \mathrm{H}, \mathrm{H}-2 \mathrm{ax}\right)$.

O-3-Azido-3-deoxy-6-O-pivaloyl- $\alpha$-D-glucopyranosyl-(1 $\rightarrow 6)-O-[2,6-d i a z i d o-2,3,6-t r i d e o x y-\alpha-D-r i b o-$ hexopyranosyl-(1 $\rightarrow 4)$ ]-1,3-diazido-1,2,3-trideoxy-D-myo-inositol (11). A solution of compound 10 $(500 \mathrm{mg}, 0.84 \mathrm{mmol})$ in pyridine $(3 \mathrm{~mL})$ at $0{ }^{\circ} \mathrm{C}$ was treated with trimethylacetyl chloride $(0.12 \mathrm{~mL}$, $1.01 \mathrm{mmol}$ ) and the resulting mixture was stirred at $0{ }^{\circ} \mathrm{C}$ for $4 \mathrm{~h}$. Progress of the reaction was monitored by TLC (Hexanes:EtOAc/2:3, $\mathrm{R}_{f} 0.38$ ). Upon completion, the reaction was quenched with $\mathrm{H}_{2} \mathrm{O}$ and extracted with EtOAc $(2 \times)$. The combined organic layers were washed with $\mathrm{H}_{2} \mathrm{O}$ and brine, dried over anhydrous $\mathrm{MgSO}_{4}$, filtered, and concentrated to give a crude product. Purification by flash column chromatography $\left(\mathrm{SiO}_{2}\right.$, Hexanes:EtOAc/3:2) gave compound 11 (360 mg, 63\%) as a colorless liquid: ${ }^{1} \mathrm{H}-\mathrm{NMR}\left(400 \mathrm{MHz}, \mathrm{CD}_{3} \mathrm{OD}\right.$, Figure S19) $\delta 5.60\left(\mathrm{~d}, J=3.6 \mathrm{~Hz}, 1 \mathrm{H}, \mathrm{H}-1^{\prime}\right), 5.26(\mathrm{~d}$, $\left.J=4.0 \mathrm{~Hz}, 1 \mathrm{H}, \mathrm{H}^{\prime \prime}{ }^{\prime \prime}\right), 4.35\left(\mathrm{dd}, J_{1}=11.6 \mathrm{~Hz}, J_{2}=2.0 \mathrm{~Hz}, 1 \mathrm{H}\right), 4.29\left(\mathrm{ddd}, J_{1}=10.0 \mathrm{~Hz}, J_{2}=4.4 \mathrm{~Hz}\right.$, $\left.J_{3}=2.0 \mathrm{~Hz}, 1 \mathrm{H}\right), 4.12\left(\mathrm{dd}, J_{1}=12.0 \mathrm{~Hz}, J_{2}=4.8 \mathrm{~Hz}, 1 \mathrm{H}\right), 4.08\left(\mathrm{ddd}, J_{1}=10.0 \mathrm{~Hz}, J_{2}=5.6 \mathrm{~Hz}, J_{3}=2.0 \mathrm{~Hz}\right.$, $1 \mathrm{H}), 3.69-3.62(\mathrm{~m}, 3 \mathrm{H}), 3.61\left(\mathrm{dd}, J_{1}=11.2 \mathrm{~Hz}, J_{2}=4.0 \mathrm{~Hz}, 1 \mathrm{H}\right), 3.55\left(\mathrm{ddd}, J_{1}=11.2 \mathrm{~Hz}, J_{2}=4.8 \mathrm{~Hz}\right.$, $\left.J_{3}=2.0 \mathrm{~Hz}, 1 \mathrm{H}\right), 3.51\left(\mathrm{dd}, J_{1}=8.0 \mathrm{~Hz}, J_{2}=2.0 \mathrm{~Hz}, 1 \mathrm{H}\right), 3.50(\mathrm{~m}, 1 \mathrm{H}), 3.48\left(\mathrm{dd}, J_{1}=13.6 \mathrm{~Hz}, J_{2}=2.8 \mathrm{~Hz}\right.$, $1 \mathrm{H}), 3.40\left(\mathrm{dd}, J_{1}=10.4 \mathrm{~Hz}, J_{2}=3.6 \mathrm{~Hz}, 1 \mathrm{H}\right), 3.39-3.31(\mathrm{~m}, 2 \mathrm{H}), 3.20\left(\mathrm{dt}, J_{1}=12.8 \mathrm{~Hz}, J_{2}=J_{3}=4.0 \mathrm{~Hz}\right.$, $1 \mathrm{H}), 2.38\left(\mathrm{dt}, J_{1}=12.8 \mathrm{~Hz}, J_{2}=J_{3}=4.0 \mathrm{~Hz}, 1 \mathrm{H}, \mathrm{H}-2 \mathrm{eq}\right), 2.14\left(\mathrm{dt}, J_{1}=11.2 \mathrm{~Hz}, J_{2}=J_{3}=4.8 \mathrm{~Hz}, 1 \mathrm{H}\right.$, H-3'eq), 1.99 (app. q, $J_{1}=J_{2}=J_{3}=12.4 \mathrm{~Hz}, 1 \mathrm{H}, \mathrm{H}-3^{\prime}$ ax), 1.54 (app. q, $J_{1}=J_{2}=J_{3}=12.4 \mathrm{~Hz}, 1 \mathrm{H}, \mathrm{H}-2 \mathrm{ax}$ ), $1.18(\mathrm{~s}, 9 \mathrm{H}) ;{ }^{13} \mathrm{C}-\mathrm{NMR}\left(100 \mathrm{MHz}, \mathrm{CD}_{3} \mathrm{OD}\right.$, Figure S20) $\delta 178.6,97.9,97.0,80.2,79.2,74.9,72.7,70.8,70.0$, 68.7, 66.7, 65.1, 62.9, 60.5, 59.3, 56.4, 51.1, 38.6, 32.0, 30.8, 26.2 (3 carbons); HR-MS (Figure S21) calcd for $\mathrm{C}_{23} \mathrm{H}_{35} \mathrm{~N}_{15} \mathrm{O}_{10} \mathrm{Na}[\mathrm{M}+\mathrm{Na}]^{+}$704.2589; found 704.2589.

O-3-Azido-3-deoxy-2,4-bis-O-(phenylmethyl)-6-O-pivaloyl- $\alpha$-D-glucopyranosyl-(1 $\rightarrow 6)-O-[2,6$-diazido2,3,6-trideoxy-4-O-(phenylmethyl)- $\alpha$-D-ribo-hexopyranosyl-(1 $\rightarrow 4)]-1,3-d i a z i d o-1,2,3-t r i d e o x y-5-O-$ (phenylmethyl)-D-myo-inositol (12). A solution of compound 11 (355 mg, $0.52 \mathrm{mmol}$ ) in DMF (3 mL) at $0{ }^{\circ} \mathrm{C}$ was treated with $60 \%$ sodium hydride $(125 \mathrm{mg}, 3.13 \mathrm{mmol})$. The reaction mixture was stirred at $0{ }^{\circ} \mathrm{C}$ for $15 \mathrm{~min}$ followed by the addition of benzyl bromide $(0.37 \mathrm{~mL}, 3.13 \mathrm{mmol})$ and TBAI (96 mg, $0.26 \mathrm{mmol}$ ). The reaction mixture was allowed to warm to room temperature and stirred overnight. Progress of the reaction was monitored by TLC (Hexanes:EtOAc/5:1, $\mathrm{R}_{f}$ 0.44). The reaction mixture was quenched with $\mathrm{H}_{2} \mathrm{O}$ and extracted with EtOAc $(2 \times)$. The combined organic layers were washed with $\mathrm{H}_{2} \mathrm{O}$ and brine, dried over anhydrous $\mathrm{MgSO}_{4}$, filtered, and concentrated to give a crude product. Purification by flash column chromatography $\left(\mathrm{SiO}_{2}\right.$, pure Hexanes to Hexanes:EtOAc/4:1) gave compound 12 (410 mg, 76\%) as a white foam: ${ }^{1} \mathrm{H}-\mathrm{NMR}\left(400 \mathrm{MHz}, \mathrm{CDCl}_{3}\right.$, Figure S22) $\delta 7.43-7.25\left(\mathrm{~m}, 13 \mathrm{H}\right.$, aromatic), $7.20\left(\mathrm{dd}, J_{1}=7.6 \mathrm{~Hz}, J_{2}=4.0 \mathrm{~Hz}, 2 \mathrm{H}\right.$, aromatic), 7.10-7.06 $\left(\mathrm{m}, 3 \mathrm{H}\right.$, aromatic), $7.04\left(\mathrm{dd}, J_{1}=7.6 \mathrm{~Hz}, J_{2}=3.6 \mathrm{~Hz}, 2 \mathrm{H}\right.$, aromatic $), 5.64\left(\mathrm{~d}, J=3.6 \mathrm{~Hz}, 1 \mathrm{H}, \mathrm{H}-1^{\prime}\right), 5.43$ $\left(\mathrm{d}, J=4.0 \mathrm{~Hz}, 1 \mathrm{H}, \mathrm{H}-1^{\prime \prime}\right), 4.96(\mathrm{~d}, J=12.0 \mathrm{~Hz}, 1 \mathrm{H}), 4.92(\mathrm{~d}, J=12.0 \mathrm{~Hz}, 1 \mathrm{H}), 4.81(\mathrm{~d}, J=11.6 \mathrm{~Hz}, 1 \mathrm{H})$, $4.73(\mathrm{~d}, J=11.6 \mathrm{~Hz}, 1 \mathrm{H}), 4.65(\mathrm{~d}, J=10.8 \mathrm{~Hz}, 1 \mathrm{H}), 4.63(\mathrm{~d}, J=11.2 \mathrm{~Hz}, 1 \mathrm{H}), 4.44(\mathrm{~d}, J=11.2 \mathrm{~Hz}, 1 \mathrm{H})$, $4.28(\mathrm{~d}, J=11.2 \mathrm{~Hz}, 1 \mathrm{H}), 4.19\left(\mathrm{ddd}, J_{1}=9.6 \mathrm{~Hz}, J_{2}=4.4 \mathrm{~Hz}, J_{3}=2.0 \mathrm{~Hz}, 1 \mathrm{H}\right), 4.03\left(\mathrm{dd}, J_{1}=12.0 \mathrm{~Hz}\right.$, 
$\left.J_{2}=2.4 \mathrm{~Hz}, 1 \mathrm{H}\right), 3.92\left(\mathrm{dd}, J_{1}=10.0 \mathrm{~Hz}, J_{2}=2.4 \mathrm{~Hz}, 1 \mathrm{H}\right), 3.80$ (app. $\left.\mathrm{t}, J_{1}=J_{2}=10.0 \mathrm{~Hz}, 1 \mathrm{H}\right), 3.72-3.50$ $(\mathrm{m}, 6 \mathrm{H}), 3.48-3.38(\mathrm{~m}, 3 \mathrm{H}), 3.31\left(\mathrm{dd}, J_{1}=10.8 \mathrm{~Hz}, J_{2}=4.0 \mathrm{~Hz}, 1 \mathrm{H}\right), 3.10\left(\right.$ app. $\left.\mathrm{t}, J_{1}=J_{2}=9.6 \mathrm{~Hz}, 1 \mathrm{H}\right)$, $2.99\left(\mathrm{dt}, J_{1}=13.2 \mathrm{~Hz}, J_{2}=J_{3}=4.0 \mathrm{~Hz}, 1 \mathrm{H}\right), 2.39\left(\mathrm{dt}, J_{1}=13.6 \mathrm{~Hz}, J_{2}=J_{3}=4.4 \mathrm{~Hz}, 1 \mathrm{H}, \mathrm{H}-2 \mathrm{eq}\right), 2.31(\mathrm{dt}$, $J_{1}=11.6 \mathrm{~Hz}, J_{2}=J_{3}=4.4 \mathrm{~Hz}, 1 \mathrm{H}, \mathrm{H}-3^{\prime}$ eq), 1.99 (app. q, $J_{1}=J_{2}=J_{3}=12.4 \mathrm{~Hz}, 1 \mathrm{H}, \mathrm{H}-3^{\prime}$ ax), 1.62 (app. q, $\left.J_{1}=J_{2}=J_{3}=12.8 \mathrm{~Hz}, 1 \mathrm{H}, \mathrm{H}-2 \mathrm{ax}\right), 1.16(\mathrm{~s}, 9 \mathrm{H}) ;{ }^{13} \mathrm{C}-\mathrm{NMR}\left(100 \mathrm{MHz}, \mathrm{CDCl}_{3}\right.$, Figure S23) $\delta 177.9,137.44$, 137.40, 137.2, 137.1, 128.54 ( 2 carbons), 128.52 (2 carbons), 128.3 (4 carbons), 128.12, 128.09 (2 carbons), 128.0, 127.9 ( 2 carbons), 127.8 ( 2 carbons), 127.7, 127.3, 125.9 ( 2 carbons), 96.3, 95.1, 83.3, 77.8, 77.2, 77.1, 76.4, 75.0, 74.7, 73.1, 71.8, 71.0, 70.8, 68.7, 65.1, 62.3, 60.2, 59.4, 56.2, 51.2, 38.8, 31.9, 27.8, 27.2 (3 carbons); HR-MS (Figure S24) calcd for $\mathrm{C}_{51} \mathrm{H}_{59} \mathrm{~N}_{15} \mathrm{O}_{10} \mathrm{Na}[\mathrm{M}+\mathrm{Na}]^{+}$1064.4467; found 1064.4483.

O-3-Azido-3-deoxy-2,4-bis-O-(phenylmethyl)- $\alpha$-D-glucopyranosyl-( $1 \rightarrow 6)$-O-[2,6-diazido-2,3,6-trideoxy4-O-(phenylmethyl)- $\alpha$-D-ribo-hexopyranosyl-(1 $\rightarrow 4)$ ]-1,3-diazido-1,2,3-trideoxy-5-O-(phenylmethyl)-Dmyo-inositol (13). A solution of compound 12 (395 mg, $0.38 \mathrm{mmol})$ was dissolved in $\mathrm{MeOH}(5 \mathrm{~mL})$, and sodium metal $(3.3 \mathrm{mg}, 0.14 \mathrm{mmol})$ was added. The resulting mixture was stirred at $60{ }^{\circ} \mathrm{C}$ for $6 \mathrm{~h}$ and progress of the reaction was monitored by TLC (Hexanes:EtOAc/4:1, $\mathrm{R}_{f} 0.20$ ). The reaction was quenched with $\mathrm{H}_{2} \mathrm{O}$ and $\mathrm{MeOH}$ was removed. The resulting mixture was extracted with EtOAc $(2 \times)$. The combined organic layers were washed with $\mathrm{H}_{2} \mathrm{O}$ and brine, dried over anhydrous $\mathrm{MgSO}_{4}$, filtered, and concentrated to give a crude product. Purification by flash column chromatography $\left(\mathrm{SiO}_{2}\right.$, Hexanes:EtOAc $\left./ 4: 1\right)$ gave compound $13(294 \mathrm{mg}, 81 \%)$ as a white solid: ${ }^{1} \mathrm{H}-\mathrm{NMR}(400 \mathrm{MHz}$, $\mathrm{CDCl}_{3}$, Figure S25) $\delta 7.43-7.26\left(\mathrm{~m}, 13 \mathrm{H}\right.$, aromatic), $7.20\left(\mathrm{dd}, J_{1}=6.8 \mathrm{~Hz}, J_{2}=2.8 \mathrm{~Hz}, 2 \mathrm{H}\right.$, aromatic), 7.13-7.08 (m, 5H, aromatic), $5.58\left(\mathrm{~d}, J=4.0 \mathrm{~Hz}, 1 \mathrm{H}, \mathrm{H}-1^{\prime}\right), 5.42\left(\mathrm{~d}, J=3.6 \mathrm{~Hz}, 1 \mathrm{H}, \mathrm{H}-1^{\prime \prime}\right), 4.94(\mathrm{~d}$, $J=11.6 \mathrm{~Hz}, 1 \mathrm{H}), 4.90(\mathrm{~d}, J=11.6 \mathrm{~Hz}, 1 \mathrm{H}), 4.80(\mathrm{~d}, J=12.0 \mathrm{~Hz}, 1 \mathrm{H}), 4.74(\mathrm{~d}, J=11.6 \mathrm{~Hz}, 1 \mathrm{H}), 4.68(\mathrm{~d}$, $J=11.6 \mathrm{~Hz}, 1 \mathrm{H}), 4.63(\mathrm{~d}, J=11.2 \mathrm{~Hz}, 1 \mathrm{H}), 4.44(\mathrm{~d}, J=11.2 \mathrm{~Hz}, 1 \mathrm{H}), 4.41(\mathrm{~d}, J=11.2 \mathrm{~Hz}, 1 \mathrm{H}), 4.19$ (ddd, $\left.J_{1}=9.6 \mathrm{~Hz}, J_{2}=4.8 \mathrm{~Hz}, J_{3}=2.4 \mathrm{~Hz}, 1 \mathrm{H}\right), 3.81$ (app. $\left.\mathrm{t}, J_{1}=J_{2}=10.0 \mathrm{~Hz}, 1 \mathrm{H}\right), 3.74-3.66(\mathrm{~m}, 2 \mathrm{H}), 3.62($ app. $\left.\mathrm{t}, J_{1}=J_{2}=9.2 \mathrm{~Hz}, 1 \mathrm{H}\right), 3.58-3.50(\mathrm{~m}, 3 \mathrm{H}), 3.48-3.37(\mathrm{~m}, 4 \mathrm{H}), 3.31\left(\mathrm{dd}, J_{1}=10.8 \mathrm{~Hz}, J_{2}=3.6 \mathrm{~Hz}, 1 \mathrm{H}\right)$, 3.22 (app. t $\left.J_{1}=J_{2}=10.0 \mathrm{~Hz}, 1 \mathrm{H}\right), 3.17(\mathrm{~m}, 1 \mathrm{H}), 2.99\left(\mathrm{dt}, J_{1}=12.8 \mathrm{~Hz}, J_{2}=J_{3}=4.0 \mathrm{~Hz}, 1 \mathrm{H}\right), 2.38(\mathrm{dt}$, $\left.J_{1}=12.8 \mathrm{~Hz}, J_{2}=J_{3}=4.8 \mathrm{~Hz}, 1 \mathrm{H}, \mathrm{H}-2 \mathrm{eq}\right), 2.32\left(\mathrm{dt}, J_{1}=11.2 \mathrm{~Hz}, J_{2}=J_{3}=4.4 \mathrm{~Hz}, 1 \mathrm{H}, \mathrm{H}-3^{\prime} \mathrm{eq}\right), 1.99$ (app. q, $\left.J_{1}=J_{2}=J_{3}=12.4 \mathrm{~Hz}, 1 \mathrm{H}, \mathrm{H}-3^{\prime} \mathrm{ax}\right), 1.63$ (app. q, $\left.J_{1}=J_{2}=J_{3}=12.8 \mathrm{~Hz}, 1 \mathrm{H}, \mathrm{H}-2 \mathrm{ax}\right) ;{ }^{13} \mathrm{C}-\mathrm{NMR}(100 \mathrm{MHz}$, $\mathrm{CD}_{3} \mathrm{OD}$, Figure S26) $\delta 138.1,138.0,137.8,137.6,128.1$ (2 carbons), 128.0 (2 carbons), 127.9 (2 carbons), 127.82 ( 2 carbons), 127.78 ( 2 carbons), 127.62, 127.55 ( 2 carbons), 127.5 ( 2 carbons), 127.4, 127.1, 126.7, 125.9 ( 2 carbons), 95.9, 95.0, 83.1, 78.0, 77.3, 77.0, 75.7, 74.3, 74.1, 72.6, 72.2, 71.2, 70.7, 70.4, 65.3, 60.2, 59.8, 59.7, 56.1, 51.0, 31.4, 27.3; HR-MS (Figure S27) calcd for $\mathrm{C}_{46} \mathrm{H}_{51} \mathrm{~N}_{15} \mathrm{O}_{9} \mathrm{Na}[\mathrm{M}+\mathrm{Na}]^{+}$980.3892; found 980.3896 .

O-3-Azido-3-deoxy-6-O-dodecyl-2,4-bis-O-(phenylmethyl)- $\alpha$-D-glucopyranosyl-(1 $\rightarrow 6)$-O-[2,6-diazido2,3,6-trideoxy-4-O-(phenylmethyl)- $\alpha$-D-ribo-hexopyranosyl-(1 $\rightarrow 4)$ ]-1,3-diazido-1,2,3-trideoxy-5-O(phenylmethyl)-D-myo-inositol (14). A solution of compound $13(80 \mathrm{mg}, 0.08 \mathrm{mmol})$ in THF (1.5 mL) at $0{ }^{\circ} \mathrm{C}$ was treated with $60 \%$ sodium hydride $(20 \mathrm{mg}, 0.84 \mathrm{mmol})$. The reaction mixture was stirred at $0{ }^{\circ} \mathrm{C}$ for $15 \mathrm{~min}$ followed by the addition of 1-bromododecane $(0.20 \mathrm{~mL}, 0.84 \mathrm{mmol})$, and a catalytic amount of TBAI $(3 \mathrm{mg})$. The reaction mixture was allowed to warm to room temperature and stirred for $12 \mathrm{~h}$. Progress of the reaction was monitored by TLC (Hexanes:EtOAc/4:1, $\mathrm{R}_{f} 0.65$ ). The reaction was quenched with $\mathrm{H}_{2} \mathrm{O}$ and extracted with EtOAc $(2 \times)$. The combined organic layers were washed with $\mathrm{H}_{2} \mathrm{O}$ and brine, dried over anhydrous $\mathrm{MgSO}_{4}$, filtered, and concentrated to give a crude product. Purification by flash column chromatography $\left(\mathrm{SiO}_{2}\right.$, Hexanes:EtOAc/4:1) gave compound 14 (77 mg, 82\%) as a white solid: ${ }^{1} \mathrm{H}-\mathrm{NMR}\left(400 \mathrm{MHz}, \mathrm{CD}_{3} \mathrm{OD}\right.$, Figure S28) $\delta 7.43(\mathrm{~d}$, $J=7.6 \mathrm{~Hz}, 2 \mathrm{H}$, aromatic), $7.35(\mathrm{t}, J=7.6 \mathrm{~Hz}, 2 \mathrm{H}$, aromatic), 7.31-7.23 $(\mathrm{m}, 11 \mathrm{H}), 7.12-7.09(\mathrm{~m}, 5 \mathrm{H}$, aromatic), $5.68\left(\mathrm{~d}, J=3.6 \mathrm{~Hz}, 1 \mathrm{H}, \mathrm{H}-1^{\prime}\right), 5.44\left(\mathrm{~d}, J=3.6 \mathrm{~Hz}, 1 \mathrm{H}, \mathrm{H}-1^{\prime \prime}\right), 4.97(\mathrm{~d}, J=11.6 \mathrm{~Hz}, 1 \mathrm{H}), 4.92(\mathrm{~d}$, $J=11.6 \mathrm{~Hz}, 1 \mathrm{H}), 4.81(\mathrm{~d}, J=11.6 \mathrm{~Hz}, 1 \mathrm{H}), 4.71(\mathrm{~d}, J=11.6 \mathrm{~Hz}, 1 \mathrm{H}), 4.64(\mathrm{~d}, J=12.0 \mathrm{~Hz}, 1 \mathrm{H}), 4.63(\mathrm{~d}$, $J=11.2 \mathrm{~Hz}, 1 \mathrm{H}), 4.46(\mathrm{~d}, J=11.6 \mathrm{~Hz}, 1 \mathrm{H}), 4.40(\mathrm{~d}, J=10.8 \mathrm{~Hz}, 1 \mathrm{H}), 4.19(\mathrm{~m}, 1 \mathrm{H}), 3.85(\mathrm{~m}, 1 \mathrm{H}), 3.79-3.57$ $(\mathrm{m}, 7 \mathrm{H}), 3.52-3.44(\mathrm{~m}, 2 \mathrm{H}), 3.39\left(\mathrm{dd}, J_{1}=10.4 \mathrm{~Hz}, J_{2}=3.2 \mathrm{~Hz}, 1 \mathrm{H}\right), 3.36\left(\mathrm{dd}, J_{1}=13.6 \mathrm{~Hz}, J_{2}=5.6 \mathrm{~Hz}\right.$, $1 \mathrm{H}), 3.24\left(\mathrm{t}, J=10.0 \mathrm{~Hz}, 2 \mathrm{H}, \mathrm{OCH}_{2} \mathrm{CH}_{2} \mathrm{CH}_{2}\left(\mathrm{CH}_{2}\right)_{8} \mathrm{CH}_{3}\right), 3.18-3.05(\mathrm{~m}, 3 \mathrm{H}), 2.38\left(\mathrm{dt}, J_{1}=12.0 \mathrm{~Hz}\right.$, 
$J_{2}=J_{3}=4.4 \mathrm{~Hz}, 2 \mathrm{H}, \mathrm{H}-2 \mathrm{eq}, \mathrm{H}-3^{\prime}$ eq), 1.95 (app. q, $\left.J_{1}=J_{2}=J_{3}=11.6 \mathrm{~Hz}, 1 \mathrm{H}, \mathrm{H}-3^{\prime} \mathrm{ax}\right), 1.85$ (p, $J=3.2 \mathrm{~Hz}$, $\left.2 \mathrm{H}, \mathrm{OCH}_{2} \mathrm{CH}_{2} \mathrm{CH}_{2}\left(\mathrm{CH}_{2}\right)_{8} \mathrm{CH}_{3}\right), 1.57$ (app. q, $\left.J_{1}=J_{2}=J_{3}=12.4 \mathrm{~Hz}, 1 \mathrm{H}, \mathrm{H}-2 \mathrm{ax}\right), 1.43$ (p, J=6.8 Hz, $\left.2 \mathrm{H}, \mathrm{OCH}_{2} \mathrm{CH}_{2} \mathrm{CH}_{2}\left(\mathrm{CH}_{2}\right)_{8} \mathrm{CH}_{3}\right), 1.25\left(\mathrm{~m}, 16 \mathrm{H}, \mathrm{OCH}_{2} \mathrm{CH}_{2} \mathrm{CH}_{2}\left(\mathrm{CH}_{2}\right)_{8} \mathrm{CH}_{3}\right), 0.87(\mathrm{t}, J=6.0 \mathrm{~Hz}, 3 \mathrm{H}$, $\left.\mathrm{OCH}_{2} \mathrm{CH}_{2} \mathrm{CH}_{2}\left(\mathrm{CH}_{2}\right)_{8} \mathrm{CH}_{3}\right) ;{ }^{13} \mathrm{C}-\mathrm{NMR}\left(100 \mathrm{MHz}, \mathrm{CDCl}_{3}\right.$, Figure S29) $\delta$ 138.0, 137.4, 137.3 (2 carbons), 128.50 ( 2 carbons), 128.48 ( 2 carbons), 128.18 ( 2 carbons), 128.16 ( 2 carbons), 128.15 ( 2 carbons), 128.05, 128.02, 127.8 (2 carbons), 127.7 ( 2 carbons), 127.5, 127.1, 126.2 (2 carbons), 96.3, 95.7, 83.2, 77.6, 77.1, 75.9, $74.9,74.5,73.0,71.8,71.6,70.9,70.8,70.1,68.3,68.0,65.3,60.2,59.4,56.1,51.2,31.9,29.69,29.65,29.62$ ( 2 carbons), 29.57, 29.4, 29.3, 27.8, 26.1, 25.6, 22.7, 14.1; HR-MS (Figure S30) calcd for $\mathrm{C}_{58} \mathrm{H}_{75} \mathrm{~N}_{15} \mathrm{O}_{19} \mathrm{Na}$ $[\mathrm{M}+\mathrm{Na}]^{+} 1148.5770$; found 1148.5786 .

O-3-Deoxy-3-[[(1,1-dimethylethoxy)carbonyl]amino]-6-O-dodecyl- $\alpha$-D-glucopyranosyl-( $1 \rightarrow 6)$-O-[2,3,6trideoxy-2,6-bis[[(1,1-dimethylethoxy)carbonyl]amino]- $\alpha$-D-ribo-hexopyranosyl-(1 $\rightarrow 4)]$-2-deoxy- $N^{1}, N^{3}$ bis[(1,1-dimethylethoxy)carbonyl]-D-streptamine (15). A solution of compound 14 (95 mg, $0.084 \mathrm{mmol})$ in THF $(2 \mathrm{~mL})$ and $0.1 \mathrm{M} \mathrm{NaOH}(0.5 \mathrm{~mL})$ was treated with $1 \mathrm{M} \mathrm{PMe}_{3}$ in THF $(0.59 \mathrm{~mL}, 0.59 \mathrm{mmol})$ and the resulting mixture was stirred at $50{ }^{\circ} \mathrm{C}$ for $2 \mathrm{~h}$. Upon completion, the solvents were removed and the crude material obtained was dissolved in $5 \mathrm{~mL}$ of degassed $\mathrm{AcOH}: \mathrm{H}_{2} \mathrm{O} / 1: 3$. A catalytic amount of $\mathrm{Pd}(\mathrm{OH})_{2} / \mathrm{C}$ was added and the resulting mixture was stirred at room temperature overnight under $\mathrm{H}_{2}$ atmosphere. The following day, the mixture was filtered through celite ${ }^{\circledR}$, and the residue was washed with $\mathrm{H}_{2} \mathrm{O}$. The filtrate was freeze-dried overnight. The residue obtained was dissolved in THF $(5 \mathrm{~mL})$ and treated with $\mathrm{Boc}_{2} \mathrm{O}(110 \mathrm{mg}, 0.51 \mathrm{mmol})$ and $\mathrm{Et}_{3} \mathrm{~N}(0.14 \mathrm{~mL}, 1.01 \mathrm{mmol})$. The resulting mixture was stirred at $60^{\circ} \mathrm{C}$ for $6 \mathrm{~h}$. Progress of the reaction was monitored by TLC (Hexanes:EtOAc/2:3, $\mathrm{R}_{f} 0.34$ ). The solvents were then removed and the crude material obtained was purified by column chromatography $\left(\mathrm{SiO}_{2}\right.$, pure Hexanes to Hexanes:EtOAc/3:7) to give compound 15 (31 mg, 32\% over 3 steps) as a white solid: ${ }^{1} \mathrm{H}-\mathrm{NMR}\left(400 \mathrm{MHz}, \mathrm{CD}_{3} \mathrm{OD}\right.$, Figure S31) $\delta 5.10$ (br $\left.\mathrm{s}, 1 \mathrm{H}, \mathrm{H}-1^{\prime}\right), 5.02$ (br d, J = 3.2 Hz, 1H, H-1' $), 4.01$ (m, 1H, H-5' ), 3.70-3.30 (m, 17H, H-1, H-3, H-4, $\left.\mathrm{H}-5, \mathrm{H}-6, \mathrm{H}-2^{\prime}, \mathrm{H}-4^{\prime}, \mathrm{H}-5^{\prime}, \mathrm{H}-6^{\prime}(2 \mathrm{H}), \mathrm{H}^{\prime \prime}{ }^{\prime \prime}, \mathrm{H}-3^{\prime \prime}, \mathrm{H}-4^{\prime \prime}, \mathrm{H}^{\prime \prime} 6^{\prime \prime}(2 \mathrm{H}), \mathrm{OCH}_{2} \mathrm{CH}_{2}\left(\mathrm{CH}_{2}\right)_{9} \mathrm{CH}_{3}\right), 2.09$ (m, $1 \mathrm{H}, \mathrm{H}-2 \mathrm{eq}), 1.99$ (m, 1H, H-3'eq), 1.62 (app. q, $\left.J_{1}=J_{2}=J_{3}=12.0 \mathrm{~Hz}, 1 \mathrm{H}, \mathrm{H}-3^{\prime} \mathrm{ax}\right), 1.55$ (p, J = $6.8 \mathrm{~Hz}$, $\left.2 \mathrm{H}, \mathrm{OCH}_{2} \mathrm{CH}_{2}\left(\mathrm{CH}_{2}\right)_{9} \mathrm{CH}_{3}\right), 1.60-1.22\left(\mathrm{~m}, 64 \mathrm{H}, \mathrm{H}-2 \mathrm{ax}, 5 \times \mathrm{CO}_{2}\left(\mathrm{CH}_{3}\right)_{3}, \mathrm{OCH}_{2} \mathrm{CH}_{2}\left(\mathrm{CH}_{2}\right)_{9} \mathrm{CH}_{3}\right), 0.88$ $\left(\mathrm{t}, J=7.2 \mathrm{~Hz}, 3 \mathrm{H}, \mathrm{OCH}_{2} \mathrm{CH}_{2}\left(\mathrm{CH}_{2}\right)_{9} \mathrm{CH}_{3}\right) ;{ }^{13} \mathrm{C}-\mathrm{NMR}\left(100 \mathrm{MHz}, \mathrm{CD}_{3} \mathrm{OD}\right.$, Figure S32) $\delta 158.1,157.9$, 156.5, 156.3 ( 2 carbons), 98.2, 97.8, 82.6, 80.9, 79.3, 78.9 (2 carbons), 78.7, 75.5, 72.3, 72.1, 71.6, 70.6, 69.6, 68.6, 65.1, 55.9, 50.2, 49.7, 49.6, 40.6, 34.2, 32.9, 31.7, 29.4 ( 2 carbons), 29.35, 29.25 ( 2 carbons), 29.23, 29.1 ( 2 carbons), 27.4 (15 carbons), 25.8, 22.3, 13.0; HR-MS (Figure S33) calcd for $\mathrm{C}_{55} \mathrm{H}_{101} \mathrm{~N}_{5} \mathrm{O}_{19} \mathrm{Na}$ $[\mathrm{M}+\mathrm{Na}]^{+}$1158.6988; found 1158.7010 .

O-3-Amino-3-deoxy-6-O-dodecyl- $\alpha$-D-glucopyranosyl-(1 $\rightarrow 6)$-O-[2,6-diamino-2,3,6-trideoxy- $\alpha$-D-ribohexopyranosyl-(1 $\rightarrow 4)$ ]-2-deoxy-D-streptamine (16). Compound $15(22 \mathrm{mg}, 0.019 \mathrm{mmol})$ was treated at room temperature with neat TFA $(1 \mathrm{~mL})$ for $3 \mathrm{~min}$. The TFA was removed under reduced pressure, the residue was dissolved in a minimal volume of $\mathrm{H}_{2} \mathrm{O}$, extracted with $\mathrm{CH}_{2} \mathrm{Cl}_{2}(3 \times)$, and freeze-dried to afford compound $16(22 \mathrm{mg}, 96 \%)$ as a white foam: ${ }^{1} \mathrm{H}-\mathrm{NMR}\left(400 \mathrm{MHz}, \mathrm{D}_{2} \mathrm{O}\right.$, Figure S34) $\delta 5.61$ (d, $\left.J=3.2 \mathrm{~Hz}, 1 \mathrm{H}, \mathrm{H}-1^{\prime}\right), 4.90\left(\mathrm{~d}, J=4.0 \mathrm{~Hz}, 1 \mathrm{H}, \mathrm{H}-1^{\prime \prime}\right), 3.85-3.70\left(\mathrm{~m}, 4 \mathrm{H}, \mathrm{H}-4, \mathrm{H}-5^{\prime}, \mathrm{H}-2^{\prime \prime}, \mathrm{H}-5^{\prime \prime}\right)$, 3.67 (app. t, $\left.J_{1}=J_{2}=9.2 \mathrm{~Hz}, 1 \mathrm{H}, \mathrm{H}-5\right), 3.62-3.28\left(\mathrm{~m}, 11 \mathrm{H}, \mathrm{H}-1, \mathrm{H}-3, \mathrm{H}-6, \mathrm{H}-2^{\prime}, \mathrm{H}-4^{\prime}, \mathrm{H}-6^{\prime}(2 \mathrm{H}), \mathrm{H}-3^{\prime \prime}\right.$, $\left.\mathrm{H}-4^{\prime \prime}, \mathrm{OCH}_{2}\left(\mathrm{CH}_{2}\right)_{10} \mathrm{CH}_{3}\right), 3.25\left(\mathrm{dd}, J_{1}=14.0 \mathrm{~Hz}, J_{2}=2.8 \mathrm{~Hz}, 1 \mathrm{H}, \mathrm{H}-6^{\prime \prime}\right), 3.08\left(\mathrm{dd}, J_{1}=13.2 \mathrm{~Hz}\right.$, $\left.J_{2}=6.8 \mathrm{~Hz}, 1 \mathrm{H}, \mathrm{H}-6^{\prime \prime}\right), 2.37$ (app. dt, $\left.J_{1}=12.4 \mathrm{~Hz}, J_{2}=J_{3}=3.6 \mathrm{~Hz}, 1 \mathrm{H}, \mathrm{H}-2 \mathrm{eq}\right), 2.12$ (app. dt, $J_{1}=12.4 \mathrm{~Hz}, J_{2}=J_{3}=4.0 \mathrm{~Hz}, 1 \mathrm{H}, \mathrm{H}-3^{\prime} \mathrm{eq}$ ), 1.85 (app. q, $J_{1}=J_{2}=J_{3}=12.0 \mathrm{~Hz}, 1 \mathrm{H}, \mathrm{H}-3^{\prime}$ ax), 1.76 (app. q, $\left.J_{1}=J_{2}=J_{3}=12.8 \mathrm{~Hz}, 1 \mathrm{H}, \mathrm{H}-2 \mathrm{ax}\right), 1.39\left(\mathrm{p}, J=6.8 \mathrm{~Hz}, 2 \mathrm{H}, \mathrm{OCH}_{2} \mathrm{CH}_{2}\left(\mathrm{CH}_{2}\right)_{9} \mathrm{CH}_{3}\right), 1.20-1.00(\mathrm{~m}$, $\left.18 \mathrm{H}, \mathrm{OCH}_{2} \mathrm{CH}_{2}\left(\mathrm{CH}_{2}\right)_{9} \mathrm{CH}_{3}\right), 0.67\left(\mathrm{t}, J=7.2 \mathrm{~Hz}, 3 \mathrm{H}, \mathrm{OCH}_{2}\left(\mathrm{CH}_{2}\right)_{10} \mathrm{CH}_{3}\right) ;{ }^{13} \mathrm{C}-\mathrm{NMR}\left(100 \mathrm{MHz}, \mathrm{D}_{2} \mathrm{O}\right.$, Figure S35) $\delta 100.8,93.9,83.7,77.0,74.0,71.89,71.86,70.3,67.92,67.86,65.2,64.3,54.7,49.5,48.2,47.6$, 39.7, 31.1, 29.2, 28.7 (2 carbons), 28.62, 28.57, 28.5, 28.4, 28.3, 27.7, 25.0, 21.9, 13.3; HR-MS (Figure S36) calcd for $\mathrm{C}_{30} \mathrm{H}_{62} \mathrm{~N}_{5} \mathrm{O}_{9}[\mathrm{M}+\mathrm{H}]^{+}$636.4542; found 636.4546 . 


\subsection{Antifungal Susceptibility Testing}

The MIC values of compounds $3,4,7 \mathbf{a}, 7 \mathbf{b}, \mathbf{9}$, and $\mathbf{1 6}$, as well as the parent compound TOB and the antifungal CAS against yeasts (strains A-G (Table 1), and strains H-J, CG1-3, CP1-3, and CN1-3 (Table 2)) were evaluated in 96-well microtiter plates as described in the CLSI document M27-A3 [52] with minor modifications. The final concentrations of compounds $3,4,7 a, 7 b, 9$, and $\mathbf{1 6}$, as well as that of TOB tested in this study ranged from $0.24-62.5 \mu \mathrm{g} / \mathrm{mL}$. CAS was used as a positive control and the final concentrations tested for CAS ranged from $0.03-31.3 \mu \mathrm{g} / \mathrm{mL}$. Briefly, overnight yeast cultures were grown in yeast peptone dextrose (YPD) broth and the cell density was adjusted to an $\mathrm{OD}_{600}$ of $0.12\left(\sim 1 \times 10^{6} \mathrm{CFU} / \mathrm{mL}\right)$ by using a spectrophotometer. Yeast cell suspensions were further diluted to achieve $1-5 \times 10^{3} \mathrm{CFU} / \mathrm{mL}$ in RPMI 1640 medium, and $100 \mu \mathrm{L}$ of these yeast cells was added to 96-well microtiter plates containing RPMI 1640 medium and titrated compounds. Each test was performed in triplicate. The plates were incubated at $35^{\circ} \mathrm{C}$ for $48 \mathrm{~h}$. The MIC values for compounds $3,4,7 a, 7 b, 9$, and 16 , CAS, and TOB were defined as the lowest drug concentration that prevented visible growth (also known as MIC-0) when compared to the growth control. These data are presented in Table 1 (for strains A-G) and Table 2 (for strains H-J, CG1-3, CP1-3, and CN1-3).

Similarly, the MIC values of compounds $3,4,7 a, 7 b, 9$, and $\mathbf{1 6}$, as well as that of all control drugs against filamentous fungi (strains $\mathbf{K}-\mathbf{M}$ (Table 3)) were determined as previously described in CLSI document M38-A2 [53]. The spores were harvested from sporulating cultures growing on potato dextrose agar (PDA) by filtration through sterile glass wool and enumerated by using a hemocytometer (Hausser Scientific, Horsham, PA, USA) to obtain the desired inoculum size. Two-fold serial dilutions of compounds $3,4,7 \mathbf{a}, 7 \mathbf{b}, \mathbf{9}$, and $\mathbf{1 6}$, as well as CAS and TOB were made in sterile 96-well microtiter plates to obtain the final concentration range of $0.24-62.5 \mu \mathrm{g} / \mathrm{mL}$ for TOB and TOB derivatives as well as $0.03-31.3 \mu \mathrm{g} / \mathrm{mL}$ for CAS in the RPMI 1640 medium. The spore suspensions were added to the wells to afford a final concentration of $5 \times 10^{5}$ spores $/ \mathrm{mL}$. The plates were incubated at $35^{\circ} \mathrm{C}$ for $72 \mathrm{~h}$. The MIC values of all compounds, including compounds $3, \mathbf{4}, \mathbf{7 a}, \mathbf{7 b}, \mathbf{9}$, and $\mathbf{1 6}$ as well as CAS and TOB against filamentous fungi were based on the complete inhibition of growth (optically clear well) when compared to the growth control (MIC-0). Each test was performed in triplicate. These data are also presented in Table 3 (strains $\mathbf{K}-\mathbf{M}$ ).

\subsection{Hemolytic Activity Assays}

The hemolytic activity of compounds $3,4,7 \mathbf{a}, 7 \mathbf{b}$, and $\mathbf{9}$ as well as the parent compound TOB was determined by using previously described methods with minor modifications [23]. Murine whole blood $(1 \mathrm{~mL})$ was suspended in $4 \mathrm{~mL}$ of PBS and centrifuged at $1000 \mathrm{rpm}$ for $10 \mathrm{~min}$ at room temperature to obtain murine red blood cells (mRBCs). The mRBCs were washed four times in PBS and resuspended in the same buffer to a final concentration of $10^{7}$ erythrocytes $/ \mathrm{mL}$. Two-fold serial dilutions of compounds 3, 4, 7a, $7 \mathbf{b}$, and 9 were prepared using $100 \mu \mathrm{L}$ of PBS buffer in Eppendorf tubes followed by the addition of $100 \mu \mathrm{L}$ of $\mathrm{mRBC}$ suspension that made the final concentration of compounds and $\mathrm{mRBC}$ s to be $0.48-62.5 \mu \mathrm{g} / \mathrm{mL}$ and $5 \times 10^{6}$ erythrocytes $/ \mathrm{mL}$, respectively. The tubes were incubated at $37{ }^{\circ} \mathrm{C}$ for $1 \mathrm{~h}$. The tubes with PBS buffer $(200 \mu \mathrm{L})$ and Triton X-100 ${ }^{\circledR}(1 \% v / v, 2 \mu \mathrm{L})$ served as the negative (blank) and positive controls, respectively. The percentage of hemolysis was calculated using the following equation: \% hemolysis $=[$ (absorbance of sample) - (absorbance of blank) $] \times 100 /$ (absorbance of positive control). These data are presented in Figure 1 and Table S1.

\subsection{In Vitro Cytotoxicity Assays}

Mammalian cytotoxicity assays were performed as previously described with minor modifications [29]. The normal human bronchial epithelial cells BEAS-2B and the human lung carcinoma epithelial cells A549 were grown in DMEM containing 10\% fetal bovine serum (FBS) and $1 \%$ antibiotics. The confluent cells were then trypsinized with $0.05 \%$ trypsin and $0.53 \mathrm{mM}$ EDTA, and resuspended in fresh DMEM medium. The cells were transferred into 96-well microtiter plates at 
a density of 3000 cells/well and were grown for $24 \mathrm{~h}$. The following day, the medium was replaced by a fresh culture medium containing serially diluted compounds $3, \mathbf{4}, \mathbf{7 a}, \mathbf{7 b}$, and $\mathbf{9}$, as well as the parent drug TOB at final concentrations of $0.48-62.5 \mu \mathrm{g} / \mathrm{mL}$ or sterile $\mathrm{ddH}_{2} \mathrm{O}$ (negative control). The cells were incubated for an additional $24 \mathrm{~h}$ at $37{ }^{\circ} \mathrm{C}$ with $5 \% \mathrm{CO}_{2}$ in a humidified incubator. To evaluate cell survival, each well was treated with $10 \mu \mathrm{L}(25 \mu \mathrm{g} / \mathrm{mL})$ of resazurin sodium salt (Sigma-Aldrich) for 4-6 h. Metabolically active cells can convert resazurin (blue) to the highly fluorescent dye resorufin (pink), which was detected at $\lambda_{560}$ excitation and $\lambda_{590}$ emission wavelengths by using a SpectraMax M5 plate reader. Triton $X-100^{\circledR}(1 \% v / v)$ gave the complete loss of cell viability and was used as the positive control. The percentage survival rates were calculated by using the following formula: $\%$ cell survival $=[($ fluorescence of sample $)-($ fluorescence of blank $)] \times 100 /[($ fluorescence of negative control) - (fluorescence of blank)]. These data are presented in Figure 2.

\subsection{Time-Kill Assays}

Time-kill assays were used to assess the inhibitory efficiency of $\mathbf{7 b}$ against three yeast strains, C. albicans ATCC 10231 (strain A), C. parapsilosis ATCC 22019 (strain J), and C. neoformans clinical isolate CN1. The protocol for time-kill assays followed methods previously described [29,54] with minor modifications. Yeast cultures were grown overnight in YPD broth at $35^{\circ} \mathrm{C}$ with shaking (200 rpm). A working stock of fungal cells was made by diluting cultures in RPMI 1640 medium to an OD 600 of 0.125 , approximately $1 \times 10^{6} \mathrm{CFU} / \mathrm{mL}$. From the working stock, $100 \mu \mathrm{L}$ of cells was added to $4.9 \mathrm{~mL}$ of RPMI 1640 medium in sterile culture tubes, making the starting fungal cell concentration approximately $10^{5} \mathrm{CFU} / \mathrm{mL}$. Compounds were then added to the fungal cells. The treatment conditions included sterile control, growth control, TOB (parent; negative control), voriconazole (VOR) at $1 \times$ MIC (positive control), $7 \mathbf{b}$ at $1 \times$ and $4 \times$ MIC. The treated fungal cultures were incubated at $35{ }^{\circ} \mathrm{C}$ with shaking (200 rpm) for $24 \mathrm{~h}$. The samples were taken from the different treatments at regular time points $(0,3,6$, 9,12 , and 24 h.) and plated in duplicates. For each time point, cultures were vortexed, $100 \mu \mathrm{L}$ of culture was aspirated, and 10-fold serial dilutions were made in sterile $\mathrm{ddH}_{2} \mathrm{O}$. From the appropriate dilutions, $100 \mu \mathrm{L}$ of fungal suspension was spread on PDA plates and incubated at $35^{\circ} \mathrm{C}$ for $48 \mathrm{~h}$ before the colony counts were determined. At $24 \mathrm{~h}, 50 \mu \mathrm{L}$ of $1 \mathrm{mM}$ resazurin was added to the treatments and incubated at $35{ }^{\circ} \mathrm{C}$ with rotation for $2 \mathrm{~h}$ in the dark for visual inspection. Experiments were performed in duplicate. These data are presented in Figure 3.

\subsection{Membrane Permeabilization Assay Using Propidium Iodide Staining}

A fresh culture of C. albicans ATCC 10231 (strain A) was prepared in $5 \mathrm{~mL}$ of YPD broth in a Falcon tube and was grown overnight at $35^{\circ} \mathrm{C}$ at $200 \mathrm{rpm}$. An overnight culture $(40 \mu \mathrm{L})$ was transferred to RPMI 1640 medium ( $1 \mathrm{~mL}$ ) containing no drug (negative control) or compound $7 \mathbf{b}$ at concentrations of $3.9 \mu \mathrm{g} / \mathrm{mL}(2 \times \mathrm{MIC})$ and $7.8 \mu \mathrm{g} / \mathrm{mL}(4 \times \mathrm{MIC})$. TOB $(31.3 \mu \mathrm{g} / \mathrm{mL})$ was used as a negative control. The cell suspensions were then treated for $2 \mathrm{~h}$ at $35^{\circ} \mathrm{C}$ with continuous agitation ( $\left.200 \mathrm{rpm}\right)$. To prepare a positive control sample, C. albicans ATCC 10231 (strain A) cells were killed by heat shock at $95^{\circ} \mathrm{C}$ for $5 \mathrm{~min}$ as described by Ocampo and Barrientos [55]. The cells were then centrifuged and resuspended in $500 \mu \mathrm{L}$ of PBS buffer ( $\mathrm{pH} 7.2$ adjusted at room temperature). Subsequently, the cells were treated with propidium iodide ( $9 \mu \mathrm{M}$, final concentration) and incubated for $20 \mathrm{~min}$ at room temperature in the dark. Glass slides prepared with $10 \mu \mathrm{L}$ of each mixture were observed in bright field and fluorescence modes (using Texas red filter set with $\lambda_{535}$ excitation and $\lambda_{617}$ emission wavelengths) using a Zeiss Axiovert $200 \mathrm{M}$ fluorescence microscope. The data were obtained from at least two independent experiments. The images were also post-processed, utilizing automatic contrast and brightness setting in Microsoft PowerPoint 2013 to eliminate background noise. These images are presented in Figure 4.

Supplementary Materials: The supplementary materials include ${ }^{1} \mathrm{H}$ and ${ }^{13} \mathrm{C}-\mathrm{NMR}$ as well as mass spectra (Figures S1-S36) for the molecules synthesized. All compounds tested for activity are $\geq 95 \%$ pure according to NMR spectra. Table S1 with the \% hemolysis \pm SDEV displayed in Figure 1 is also provided. These materials are available free of charge via the Internet. 
Acknowledgments: This work was supported by NIH grant AI090048 (to S.G.-T.).

Author Contributions: M.Y.F., N.T.C. and S.G.-T. conceived and designed the study; M.Y.F. and N.T.C. performed the syntheses; S.K.S., E.K.D. and K.D.G. performed the biological studies; M.Y.F. and S.G.-T. analyzed the data and wrote the paper.

Conflicts of Interest: The authors declare no conflict of interest.

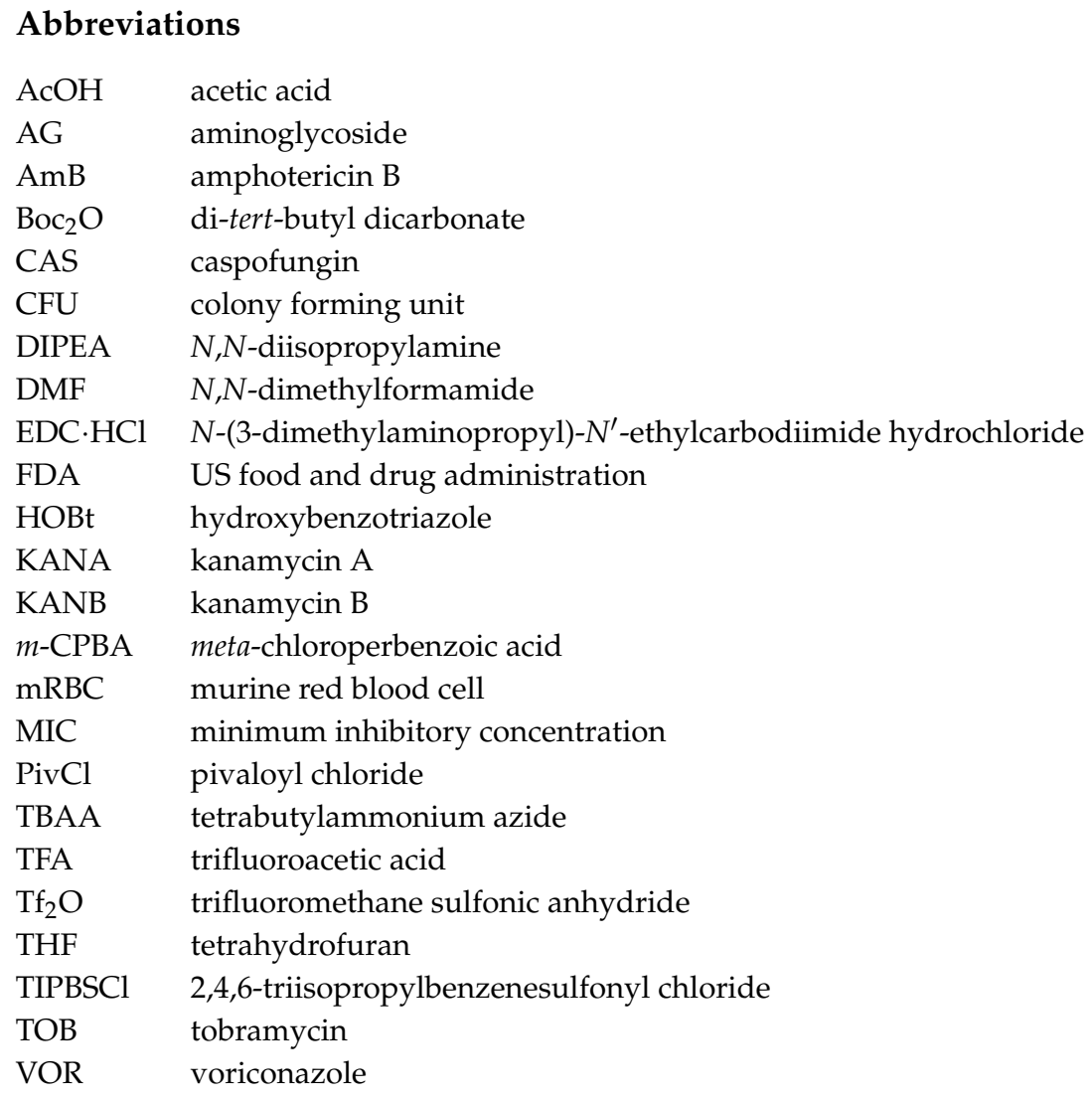

\section{References}

1. Houghton, J.L.; Green, K.D.; Chen, W.; Garneau-Tsodikova, S. The future of aminoglycosides: The end or renaissance? ChemBioChem 2010, 11, 880-902. [CrossRef] [PubMed]

2. Garneau-Tsodikova, S.; Labby, K.J. Mechanisms of resistance to aminoglycoside antibiotics: Overview and perspectives. MedChem Comm 2016, 7, 11-27. [CrossRef] [PubMed]

3. Thamban Chandrika, N.; Garneau-Tsodikova, S. Comprehensive review of chemical strategies for the preparation of new aminoglycosides and their biological activities. Chem. Soc. Rev. 2018, 47, 1189-1249. [CrossRef] [PubMed]

4. Gorityala, B.K.; Guchhait, G.; Schweizer, F. Amphiphilic aminoglycoside antimicrobials in antibacterial discovery. In Carbohydrates in Drug Design and Discovery; Royal Society of Chemistry: Cambridge, UK, 2015; pp. 255-285.

5. Bera, S.; Zhanel, G.G.; Schweizer, F. Antibacterial activities of aminoglycoside antibiotics-derived cationic amphiphiles. Polyol-modified neomycin B-, kanamycin A-, amikacin-, and neamine-based amphiphiles with potent broad spectrum antibacterial activity. J. Med. Chem. 2010, 53, 3626-3631. [CrossRef] [PubMed]

6. Dhondikubeer, R.; Bera, S.; Zhanel, G.G.; Schweizer, F. Antibacterial activity of amphiphilic tobramycin. J. Antibiot. 2012, 65, 495-498. [CrossRef] [PubMed]

7. Berkov-Zrihen, Y.; Herzog, I.M.; Benhamou, R.I.; Feldman, M.; Steinbuch, K.B.; Shaul, P.; Lerer, S.; Eldar, A.; Fridman, M. Tobramycin and nebramine as pseudo-oligosaccharide scaffolds for the development of antimicrobial cationic amphiphiles. Chemistry 2015, 21, 4340-4349. [CrossRef] [PubMed] 
8. Herzog, I.M.; Green, K.D.; Berkov-Zrihen, Y.; Feldman, M.; Vidavski, R.R.; Eldar-Boock, A.; Satchi-Fainaro, R.; Eldar, A.; Garneau-Tsodikova, S.; Fridman, M. 6"-thioether tobramycin analogues: Towards selective targeting of bacterial membranes. Angew. Chem. 2012, 51, 5652-5656. [CrossRef] [PubMed]

9. Guchhait, G.; Altieri, A.; Gorityala, B.; Yang, X.; Findlay, B.; Zhanel, G.G.; Mookherjee, N.; Schweizer, F. Amphiphilic tobramycins with immunomodulatory properties. Angew. Chem. 2015, 54, 6278-8622. [CrossRef] [PubMed]

10. Fosso, M.Y.; Zhu, H.; Green, K.D.; Garneau-Tsodikova, S.; Fredrick, K. Tobramycin variants with enhanced ribosome-targeting activity. ChemBioChem 2015, 16, 1565-1570. [CrossRef] [PubMed]

11. Herzog, I.M.; Feldman, M.; Eldar-Boock, A.; Satchi-Fainaro, R.; Fridman, M. Design of membrane targeting tobramycin-based cationic amphiphiles with reduced hemolytic activity. MedChem Comm 2013, 4, 120-124. [CrossRef]

12. Baussanne, I.; Bussiere, A.; Halder, S.; Ganem-Elbaz, C.; Ouberai, M.; Riou, M.; Paris, J.M.; Ennifar, E.; Mingeot-Leclercq, M.P.; Decout, J.L. Synthesis and antimicrobial evaluation of amphiphilic neamine derivatives. J. Med. Chem. 2010, 53, 119-127. [CrossRef] [PubMed]

13. Ouberai, M.; El Garch, F.; Bussiere, A.; Riou, M.; Alsteens, D.; Lins, L.; Baussanne, I.; Dufrene, Y.F.; Brasseur, R.; Decout, J.L.; et al. The Pseudomonas aeruginosa membranes: A target for a new amphiphilic aminoglycoside derivative? Biochim. Biophys. Acta 2011, 1808, 1716-1727. [CrossRef] [PubMed]

14. Sautrey, G.; Zimmermann, L.; Deleu, M.; Delbar, A.; Souza Machado, L.; Jeannot, K.; Van Bambeke, F.; Buyck, J.M.; Decout, J.L.; Mingeot-Leclercq, M.P. New amphiphilic neamine derivatives active against resistant Pseudomonas aeruginosa and their interactions with lipopolysaccharides. Antimicrob. Agents Chemother. 2014, 58, 4420-4430. [CrossRef] [PubMed]

15. Bera, S.; Zhanel, G.G.; Schweizer, F. Design, synthesis, and antibacterial activities of neomycin-lipid conjugates: Polycationic lipids with potent gram-positive activity. J. Med. Chem. 2008, 51, 6160-6164. [CrossRef] [PubMed]

16. Zhang, J.; Chiang, F.I.; Wu, L.; Czyryca, P.G.; Li, D.; Chang, C.W. Surprising alteration of antibacterial activity of $5^{\prime \prime}$-modified neomycin against resistant bacteria. J. Med. Chem. 2008, 51, 7563-7573. [CrossRef] [PubMed]

17. Zhang, J.; Keller, K.; Takemoto, J.Y.; Bensaci, M.; Litke, A.; Czyryca, P.G.; Chang, C.W. Synthesis and combinational antibacterial study of $5^{\prime \prime}$-modified neomycin. J. Antibiot. 2009, 62, 539-544. [CrossRef] [PubMed]

18. Bera, S.; Dhondikubeer, R.; Findlay, B.; Zhanel, G.G.; Schweizer, F. Synthesis and antibacterial activities of amphiphilic neomycin B-based bilipid conjugates and fluorinated neomycin B-based lipids. Molecules 2012, 17, 9129-9141. [CrossRef] [PubMed]

19. Udumula, V.; Ham, Y.W.; Fosso, M.Y.; Chan, K.Y.; Rai, R.; Zhang, J.; Li, J.; Chang, C.W. Investigation of antibacterial mode of action for traditional and amphiphilic aminoglycosides. Bioorg. Med. Chem. Lett. 2013, 23, 1671-1675. [CrossRef] [PubMed]

20. Francois, B.; Szychowski, J.; Adhikari, S.S.; Pachamuthu, K.; Swayze, E.E.; Griffey, R.H.; Migawa, M.T.; Westhof, E.; Hanessian, S. Antibacterial aminoglycosides with a modified mode of binding to the ribosomal-RNA decoding site. Angew. Chem. 2004, 43, 6735-6738. [CrossRef] [PubMed]

21. Berkov-Zrihen, Y.; Herzog, I.M.; Feldman, M.; Fridman, M. Site-selective displacement of tobramycin hydroxyls for preparation of antimicrobial cationic amphiphiles. Org. Lett. 2013, 15, 6144-6147. [CrossRef] [PubMed]

22. Bera, S.; Zhanel, G.G.; Schweizer, F. Antibacterial activity of guanidinylated neomycin B- and kanamycin A-derived amphiphilic lipid conjugates. J. Antimicrob. Chemother. 2010, 65, 1224-1227. [CrossRef] [PubMed]

23. Fosso, M.Y.; Shrestha, S.K.; Green, K.D.; Garneau-Tsodikova, S. Synthesis and bioactivities of kanamycin B-derived cationic amphiphiles. J. Med. Chem. 2015, 58, 9124-9132. [CrossRef] [PubMed]

24. Fosso, M.Y.; Li, Y.; Garneau-Tsodikova, S. New trends in aminoglycosides use. MedChemComm 2014, 5, 1075-1091. [CrossRef] [PubMed]

25. Chang, C.W.; Fosso, M.; Kawasaki, Y.; Shrestha, S.; Bensaci, M.F.; Wang, J.; Evans, C.K.; Takemoto, J.Y. Antibacterial to antifungal conversion of neamine aminoglycosides through alkyl modification. Strategy for reviving old drugs into agrofungicides. J. Antibiot. 2010, 63, 667-672. [CrossRef] [PubMed]

26. Shrestha, S.; Grilley, M.; Fosso, M.Y.; Chang, C.W.; Takemoto, J.Y. Membrane lipid-modulated mechanism of action and non-cytotoxicity of novel fungicide aminoglycoside FG08. PLoS ONE 2013, 8, e73843. [CrossRef] [PubMed] 
27. Chang, C.W.; Takemoto, J.Y. Antifungal amphiphilic aminoglycosides. MedChemComm 2014, 5, $1048-1057$. [CrossRef] [PubMed]

28. Fosso, M.; AlFindee, M.N.; Zhang, Q.; Nziko Vde, P.; Kawasaki, Y.; Shrestha, S.K.; Bearss, J.; Gregory, R.; Takemoto, J.Y.; Chang, C.W. Structure-activity relationships for antibacterial to antifungal conversion of kanamycin to amphiphilic analogues. J. Org. Chem. 2015, 80, 4398-4411. [CrossRef] [PubMed]

29. Shrestha, S.K.; Fosso, M.Y.; Garneau-Tsodikova, S. A combination approach to treating fungal infections. Sci. Rep. 2015, 5, 17070. [CrossRef] [PubMed]

30. Shrestha, S.K.; Chang, C.W.; Meissner, N.; Oblad, J.; Shrestha, J.P.; Sorensen, K.N.; Grilley, M.M.; Takemoto, J.Y. Antifungal amphiphilic aminoglycoside K20: Bioactivities and mechanism of action. Front. Microbiol. 2014, 5, 671. [CrossRef] [PubMed]

31. Robbins, N.; Wright, G.D.; Cowen, L.E. Antifungal drugs: The current armamentarium and development of new agents. Microbiol. Spectr. 2016, 4. [CrossRef]

32. Anderson, T.M.; Clay, M.C.; Cioffi, A.G.; Diaz, K.A.; Hisao, G.S.; Tuttle, M.D.; Nieuwkoop, A.J.; Comellas, G.; Maryum, N.; Wang, S.; et al. Amphotericin forms an extramembranous and fungicidal sterol sponge. Nat. Chem. Biol. 2014, 10, 400-406. [CrossRef] [PubMed]

33. Ghannoum, M.A.; Rice, L.B. Antifungal agents: Mode of action, mechanisms of resistance, and correlation of these mechanisms with bacterial resistance. Clin. Microbiol. Rev. 1999, 12, 501-517. [PubMed]

34. Denning, D.W. Echinocandin antifungal drugs. Lancet 2003, 362, 1142-1151. [CrossRef]

35. Shapiro, R.S.; Robbins, N.; Cowen, L.E. Regulatory circuitry governing fungal development, drug resistance, and disease. Microbiol. Mol. Biol. Rev. 2011, 75, 213-267. [CrossRef] [PubMed]

36. Pasqualotto, A.C.; Denning, D.W. New and emerging treatments for fungal infections. J. Antimicrob. Chemother. 2008, 61 (Suppl. 1), i19-i30. [CrossRef] [PubMed]

37. Shrestha, S.K.; Garzan, A.; Garneau-Tsodikova, S. Novel alkylated azoles as potent antifungals. Eur. J. Med. Chem. 2017, 133, 309-318. [CrossRef] [PubMed]

38. Thamban Chandrika, N.; Shrestha, S.K.; Ranjan, N.; Sharma, A.; Arya, D.P.; Garneau-Tsodikova, S. New application of neomycin B-bisbenzimidazole hybrids as antifungal agents. ACS Infect. Dis. 2018, 4, 196-207. [CrossRef] [PubMed]

39. Thamban Chandrika, N.; Shrestha, S.K.; Ngo, H.X.; Tsodikov, O.V.; Howard, K.C.; Garneau-Tsodikova, S. Alkylated piperazines and piperazine-azole hybrids as antifungal agents. J. Med. Chem. 2018, 61, 158-173. [CrossRef] [PubMed]

40. Thamban Chandrika, N.; Shrestha, S.K.; Ngo, H.X.; Howard, K.C.; Garneau-Tsodikova, S. Novel fluconazole derivatives with promising antifungal activity. Bioorg. Med. Chem. 2018, 26, 573-580. [CrossRef] [PubMed]

41. Holbrook, S.Y.L.; Garzan, A.; Dennis, E.K.; Shrestha, S.K.; Garneau-Tsodikova, S. Repurposing antipsychotic drugs into antifungal agents: Synergistic combinations of azoles and bromperidol derivatives in the treatment of various fungal infections. Eur. J. Med. Chem. 2017, 139, 12-21. [CrossRef] [PubMed]

42. Ngo, H.X.; Shrestha, S.K.; Garneau-Tsodikova, S. Identification of ebsulfur analogues with broad-spectrum antifungal activity. ChemMedChem 2016, 11, 1507-1516. [CrossRef] [PubMed]

43. Shrestha, S.K.; Fosso, M.Y.; Green, K.D.; Garneau-Tsodikova, S. Amphiphilic tobramycin analogues as antibacterial and antifungal agents. Antimicrob. Agents Chemother. 2015, 59, 4861-4869. [CrossRef] [PubMed]

44. Michael, K.; Wang, H.; Tor, Y. Enhanced RNA binding of dimerized aminoglycosides. Bioorg. Med. Chem. 1999, 7, 1361-1371. [CrossRef]

45. Nyffeler, P.T.; Liang, C.H.; Koeller, K.M.; Wong, C.H. The chemistry of amine-azide interconversion: Catalytic diazotransfer and regioselective azide reduction. J. Am. Chem. Soc. 2002, 124, 10773-10778. [CrossRef] [PubMed]

46. Walsh, T.J.; Groll, A.; Hiemenz, J.; Fleming, R.; Roilides, E.; Anaissie, E. Infections due to emerging and uncommon medically important fungal pathogens. Clin. Microbiol. Infect. 2004, 10 (Suppl. 1), 48-66. [CrossRef] [PubMed]

47. Pfaller, M.A.; Diekema, D.J. Epidemiology of invasive candidiasis: A persistent public health problem. Clin. Microbiol. Rev. 2007, 20, 133-163. [CrossRef] [PubMed]

48. Gullo, A. Invasive fungal infections: The challenge continues. Drugs 2009, 69 (Suppl. 1), 65-73. [CrossRef] [PubMed]

49. Caballero Van Dyke, M.C.; Wormley, F.L., Jr. A call to arms: Quest for a cryptococcal vaccine. Trends Microbiol. 2017. [CrossRef] [PubMed] 
50. Makovitzki, A.; Avrahami, D.; Shai, Y. Ultrashort antibacterial and antifungal lipopeptides. Proc. Natl. Acad. Sci. USA 2006, 103, 15997-16002. [CrossRef] [PubMed]

51. Pina-Vaz, C.; Sansonetty, F.; Rodrigues, A.G.; Costa-Oliveira, S.; Tavares, C.; Martinez-de-Oliveira, J. Cytometric approach for a rapid evaluation of susceptibility of Candida strains to antifungals. Clin. Microbiol. Infect. 2001, 7, 609-618. [CrossRef] [PubMed]

52. Clinical and Laboratory Standards Institute. Reference method for Broth Dilution Antifungal Susceptibility Testing of Yeasts-Approved Standard; CLSI Document M27-A3; Clinical and Laboratory Standards Institute: Wayne, PA, USA, 2008.

53. Clinical and Laboratory Standards Institute. Reference Method for Broth Dilution Antifungal Susceptibility Testing of Filamentous Fungi, 2nd ed.; CLSI Document M38-A2; Clinical and Laboratory Standards Institute: Wayne, PA, USA, 2008.

54. Klepser, M.E.; Malone, D.; Lewis, R.E.; Ernst, E.J.; Pfaller, M.A. Evaluation of voriconazole pharmacodynamics using time-kill methodology. Antimicrob. Agents Chemother. 2000, 44, 1917-1920. [CrossRef] [PubMed]

55. Ocampo, A.; Barrientos, A. Quick and reliable assessment of chronological life span in yeast cell populations by flow cytometry. Mech. Ageing Dev. 2011, 132, 315-323. [CrossRef] [PubMed]

Sample Availability: Samples of the compounds 3, 4, 7a, 7b, 9, and 16 are available from the authors. 